\title{
Integration of natural and technological risks in Lombardy, Italy
}

\author{
S. Lari, P. Frattini, and G. B. Crosta \\ Dipartimento di Scienze Geologiche e Geotecnologie, Università degli Studi di Milano Bicocca, Milano, Italy
}

Received: 22 July 2008 - Revised: 24 September 2009 - Accepted: 1 November 2009 - Published: 11 December 2009

\begin{abstract}
Multi-risk assessment is becoming a valuable tool for land planning, emergency management and the deployment of mitigation strategies. Multi-risk maps combine all available information about hazard, vulnerability, and exposed values related to different dangerous phenomena, and provide a quantitative support to complex decision making.

We analyse and integrate through an indicator-based approach nine major threats affecting the Lombardy Region (Northern Italy, $25000 \mathrm{~km}^{2}$ ), namely landslide, avalanche, flood, wildfire, seismic, meteorological, industrial (technological) risks; road accidents, and work injuries. For each threat, we develop a set of indicators that express the physical risk and the coping capacity or system resilience. By combining these indicators through different weighting strategies (i.e. budgetary allocation, and fuzzy logic), we calculate a total risk for each threat. Then, we integrate these risks by applying AHP (Analytic Hierarchy Process) weighting, and we derive a set of multi-risk maps. Eventually, we identify the dominant risks for each zone, and a number of risk hotspot areas.

The proposed approach can be applied with different degree of detail depending on the quality of the available data. This allows the application of the method even in case of non homogeneous data, which is often the case for regional scale analyses. Moreover, it allows the integration of different risk types or metrics.

Relative risk scores are provided from this methodology, not directly accounting for the temporal occurrence probability of the phenomena.
\end{abstract}

\section{Introduction}

In spite of a growing understanding and a great effort of society in disaster mitigation, the management and reduction of existing risks continue to challenge disaster prone com-

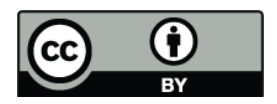

Correspondence to: S. Lari

(s.lari@campus.unimib.it) munities (Tyagunov et al., 2005). Frequency and severity of natural and technological disasters are increasing worldwide; combined with the development of urbanised areas and with the growth of population, they result in a dramatic growth of losses. Their reduction becomes a strategic goal, and is being recognized as an integral component of both emergency management and sustainable development, also involving social, economic, political, and legal issues (Durham, 2003).

Risk management is more effective when: (1) it is an integral part of a total community risk management approach, (2) it involves all levels of government and community, and (3) it is proposed as a prevention and preparedness approach, rather than purely response (Durham, 2003).

In this paper we present a methodology for multi-risk assessment that can be applied to regional scale analyses. In the following, we define risk as the measure of the probability and severity of a damage to life, health, property, and environment.

The methodology integrates information with different degree of accuracy into an indicator based approach, in order to develop a regional scale multi-risk assessment and to identify "hot spot" risk areas for more detailed analysis. Finally, we investigate the sensitivity of weights, and the effect on risk assessment of different individual attitudes and perception (i.e., expert, social, political, risk aversion).

\subsection{Background}

Risk is generally agreed to be dependent on probability of occurrence of hazardous events and on expected consequences (Baecher and Christian, 2003). According to Kaplan and Garrick (1981) risk is defined by a combination of the expected consequences of a set of scenarios, each with a probability and a consequence. If the scenarios are sorted in terms of increasing severity of the consequences, then a risk curve (F-N curve, frequency of fatal events vs. number of fatalities in such events, and F-D curve, frequency of events vs. economical damage in such events) can be plotted, illustrating for example the probability of losses exceeding a given value to occur. Hazard is the probability that a particular threat

Published by Copernicus Publications on behalf of the European Geosciences Union. 
occurs within a given period of time at a specific site (e.g. annual exceeding probability of an event of specified magnitude). In technological risk, hazard is also referred to as the probability of Accidental Event (NORSOK, 2001) or Initiating Event (Stamatelatos and Apostolakis, 2002).

Vulnerability is the predisposition of some portions of the physical, social and economical space to suffer damages in consequence of impact with potentially harmful phenomena (United Nations Development Programme, 2004). Physical vulnerability is the degree of loss to a given element or set of elements within the area affected by a hazard, and it can be expressed through a mathematical function on a scale of 0 (no loss) to 1 (total loss). Vulnerability functions are commonly available only for flood and earthquakes (Porter et al., 2001; FEMA, 1999; USACE, 2000), and in some examples for landslides (Glade et al., 2003; Roberds, 2005; Birkmann, 2006; Fuchs et al., 2007; Galli and Guzzetti, 2007; Agliardi et al., 2009).

As for the other dimensions of vulnerability, a set of heuristic or empirical indicators are reported in literature (Coburn et al., 1994; CEPAL/BID, 2000; Barbat, 2003; Glade, 2003; UNDP, 2004).

Separate investigations of single processes and risks can result misjudging and inadequate in complex areas where many threats are simultaneously present, and interacting. Multi-hazard approaches are not only valuable to get an overview on the overall risk but have also a high significance for planning effective countermeasures (Bell et al., 2004). Sometimes, mitigation strategies developed for one of the threats affecting an area can increase the risk related to another one. Where natural and human systems are strictly interacting, holistic studies are necessary to analyse the interactions and to find adequate solutions for endangered areas (Bell et al., 2004).

Despite many approaches have been proposed to assess specific natural and technological hazards and risks, only few studies combine multiple typologies into a multi-risk holistic assessment. Trans-national studies have been performed to compare risk levels in different countries (Cardona et al., 2004; UNDP, 2004; ESPON, 2005) or to identify key "hot-spots" where the risks of natural disasters are particularly high (Dilley et al., 2005). These studies are based on approaches that make use of national-level indicators (e.g., number of hazardous events, Gross Domestic Product, total population), without a spatial analysis of hazard and elementat-risk patterns.

Local scale multi-risk analyses have been proposed including multiple sources of natural (Granger et al., 1999; Granger and Hayne, 2001; Middleman and Granger, 2001; Van Westen et al., 2002) and natural/technological hazards (na-tech; Barbat and Cardona, 2003; Ferrier and Haque, 2003). These studies require an accurate description of each hazard and risk, at the temporal and spatial scale, and are suitable only for small areas already recognized as "hot spots".

\section{Study area}

Lombardy (Northern Italy) covers an area of $23855 \mathrm{~km}^{2}$. $17 \%$ of the Italian population (almost 9000000 people, ISTAT Istituto nazionale di statistica, 2006) lives in Lombardy and about $25 \%$ of the Gross Domestic Product (GDP) is produced here (ISTAT, 2005).

The region presents a wide variety of landscapes and environments, but it can roughly be subdivided into 3 different sectors: the Alps, the Po alluvial plain, and the Apennines (Fig. 1).

The Alps, to the North, cover $11940 \mathrm{~km}^{2}$, with elevations up to $4025 \mathrm{~m}$ a.s.l., are composed of three major structural domains, namely: southern Alps, Pennidic and Austroalpine domain. The East trending Insubric line bounds the southern Alps to the north. The Lombardy alpine lakes cover over $800 \mathrm{~km}^{2}$.

The Po river plain, $\left(11221 \mathrm{~km}^{2}\right)$, covers most of the southern part of the region, and half of its total area. It is a fertile plain, thanks to the abundance of water courses and springs. The plain is highly populated, and hosts intensive industrial and commercial activities. The Apennines extends for $700 \mathrm{~km}^{2}$ in the South-West of the region, with elevations up to a $1724 \mathrm{~m}$ a.s.l.

Climate is continental, with local variations related to the orographic setting. Mean annual precipitation ranges from 650 to $800 \mathrm{~mm} /$ year in the lower plain, gradually increasing towards the Alps. Here we observe a strong orographic effect, with maximum precipitation in the southern Alps (2000-2200 mm/year) and minimum values in the northern sector (700-900 mm/year).

The most populated cities (Milano, Bergamo, Brescia, Varese) are located in the upper plain area, where $80 \%$ of population and most industrial facilities, services and lifelines are located (Fig. 1).

\section{State of risks in Lombardy}

Lombardy is characterized by many risks that threaten the population and the economic activities. The Regional Civil Protection Agency (PRIM, 2007), identified nine major threats, whose analysis has been considered a priority: landslide, avalanche, flood, wildfire, seismic, meteorological, and industrial (technological) risks; road accidents, and work injuries. Some potentially relevant threats were not considered, as pollution, sanitary risks, terrorist attacks.

Landslides, floods and snow avalanches have been grouped in the "hydrogeological risk" in accordance to the standards of the Regional Civil Protection Office (PRIM, 2007).

In order to highlight the impact on the territory of the analysed threats on Lombardy, we collected data about fatalities occurred in the last century (Fig. 2). Unfortunately, data were 


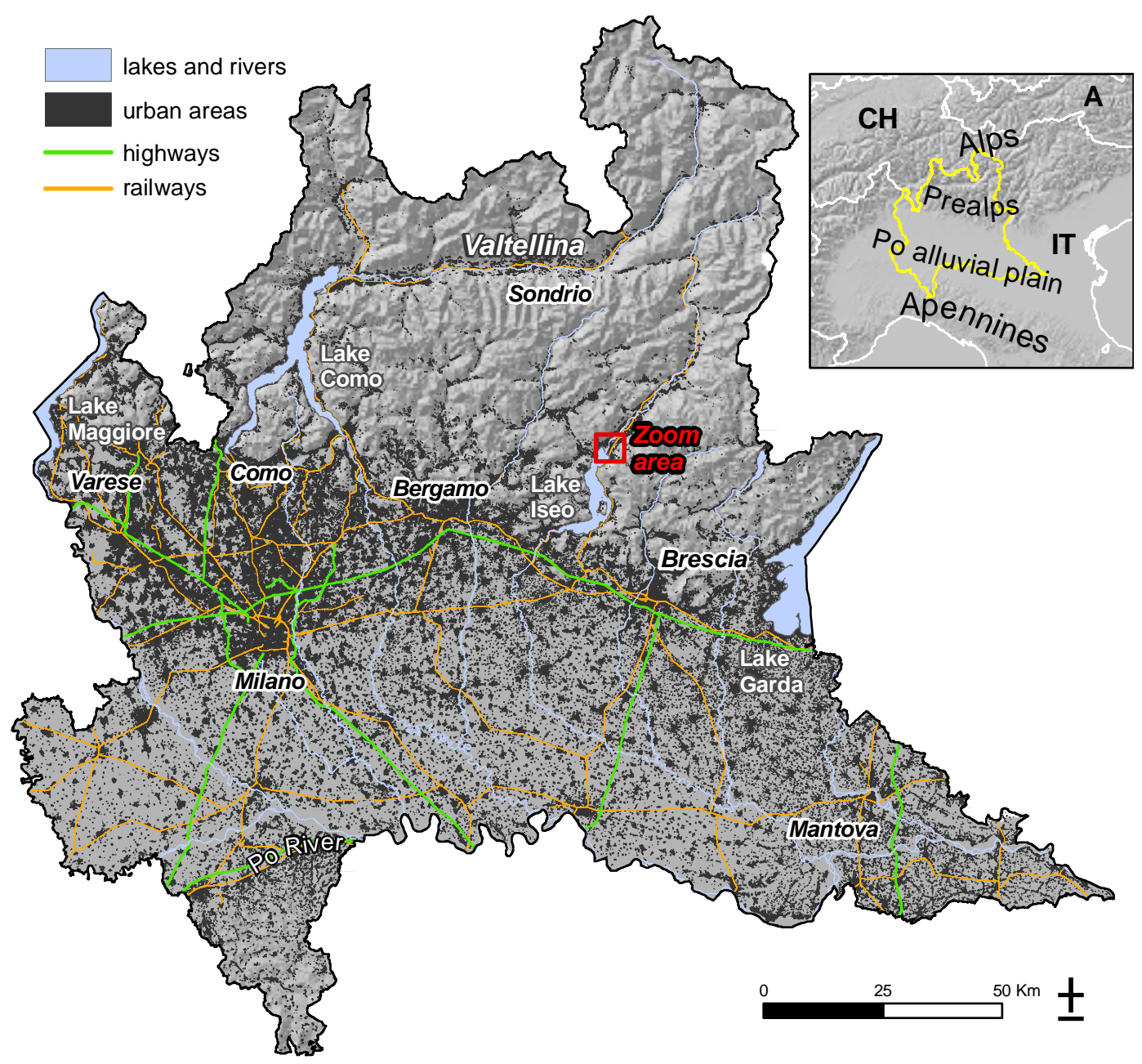

Fig. 1. Map of Lombardy. Urban areas and main transportation network used for the analysis are shown.

available only for some threats and limited time intervals, and were not usable in the successive risk analysis.

Since 1906, floods and landslides caused 421 and 239 fatalities, respectively (AVI, Aree Vulnerate Italiane da frane ed inondazioni, 2007), while snow avalanches caused 53 fatalities and a global amount of 104 injured people since 1985 (SIRVAL, Sistema Informativo Regionale Valanghe, 2007). Road accidents and work injuries show a much larger impact on human life than other risks, the annual number of fatalities being orders of magnitude higher with respect to the other risks. In the period 1999-2004 almost 45000 road accidents per year occurred causing about 800-900 fatalities per year (Fig. 2; source: ISTAT). 160000 work injuries per year were recorded on average between 2001 and 2006, with almost 200 fatalities per year (source: INAIL, national insurance for work injuries, 2007) (Fig. 2).

Wildfires and earthquakes did not have relevant consequences on human lives in the last century. Lombardy has in general a low seismic risk, with respect to other Italian regions, with some exceptions in the eastern sector, close to the Lake Garda (max historical magnitude 6 Richter, 1222 AD, Gruppo di lavoro CPTI, 2004). A moderate seismicity characterizes also the Apenninic zone (max magnitude 5.5 Richter, 1541 AD, Gruppo di lavoro CPTI, 2004), the upper Valtellina and the south eastern part of the region.

Other data that we collected to give a general overview of the state of risk in Lombardy regard the regional expenditure for risk mitigation. This is not necessarily a good proxy for risk severity, though it provides a rough idea of the economical and effective impact of different risks on the community, from the perspective of the Regional Administration, as a result of a politic perception.

The mitigation costs sustained in 2006 by public administrations for the period 2007-2010 amount to 2.1 billion $€$. $72.95 \%$ of the costs have been planned for the mitigation of road accidents, $24.89 \%$ for landslides, floods and avalanches, $0.95 \%$ for seismic risk mitigation, $0.89 \%$ for wildfires, $0.24 \%$ for industrial accidents, and $0.06 \%$ for work injuries. It is worth to note that no significant event in 2006 required planning exceptional mitigation expenditure. Thus, 


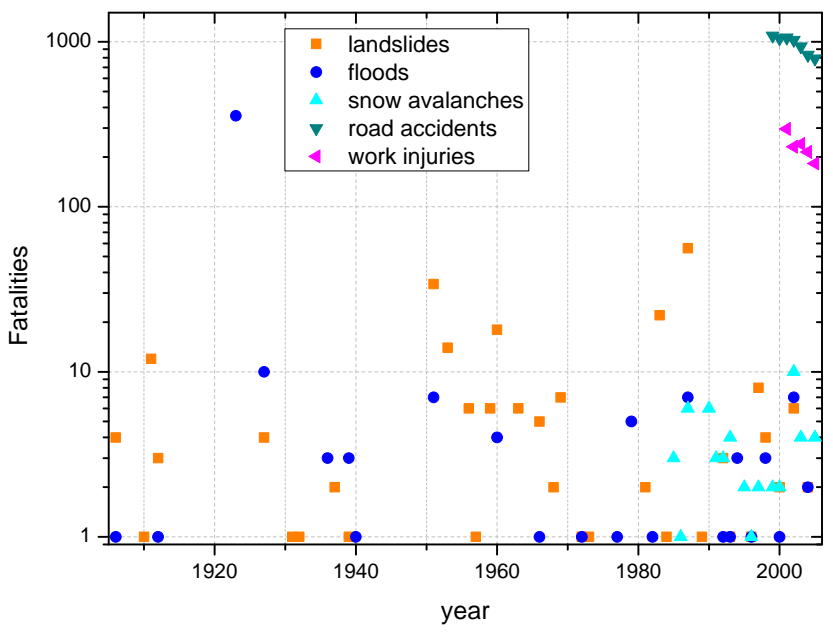

Fig. 2. Number of fatalities per year in Lombardy caused by floods and landslides between 1906 and 2005 (AVI), by avalanches between 1985 and 2005 (SIRVAL), by road accidents between 1999 and 2005 (source: ISTAT), and by work injuries in the period 20012005 (source: INAIL).

the 2006 planning can be considered representative of ordinary mitigation costs. It is also worth to note that public administration expenditures for seismic risk, industrial risk, and work injuries are not representative of the actual economic impact, because most of the mitigation costs for these risks are covered by privates or/and insurances.

Though the expenditure for road accidents and hydrogeological risk is orders of magnitude higher than the others, also the other threats have been included in the analysis. The planning of a civil protection strategy of risk management and prevention, which is the purpose of this study, needs to account for all the possible threats active and interacting in a specified territory, even if their public costs are not so relevant.

\section{General methodology}

The methodology was developed starting from available data at different scales, in order to be suitable for use at different scales and with data at different levels of detail. Risk analyses were performed at the regional scale using as terrain units $1 \mathrm{~km} \times 1 \mathrm{~km}$ square polygons. The subdivision of the study area in vector square polygons reduces the loss of spatial information with respect to the raster format. Besides, the geometry of the elements at risk and of the areas involved by dangerous processes is maintained with a high detail within each polygon. The impacted areas are calculated through geometric analysis maintaining the highest precision available, and referred only in the end to each polygon.

The constant area of terrain units ensures the homogeneity of the analysis in spatial resolution, starting from heterogeneous input data with different scale and resolution.

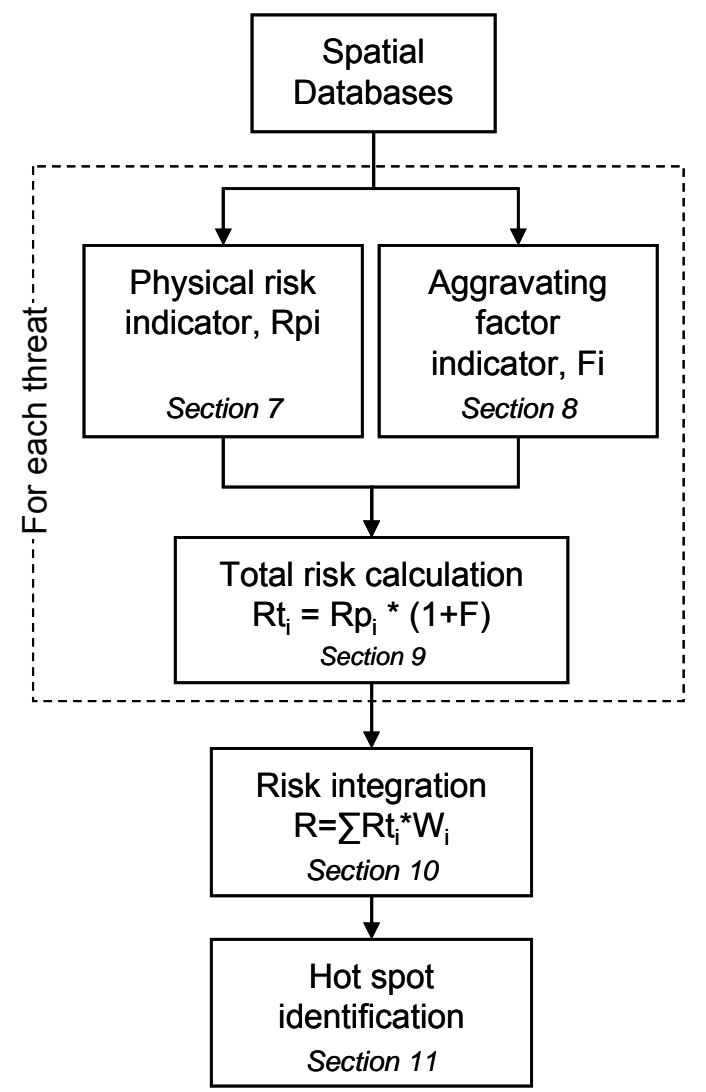

Fig. 3. Methodological scheme of the analysis. Subscript $i$ refers to each threat.

The adopted methodology for risk assessment is based on indicators (Fig. 3). These indicators are developed at different levels of complexity according to the availability of data for each threat, thus allowing both to manage heterogeneous data (in quality and quantity) and to integrate them iteratively using all the available information.

\section{Databases}

Sources of hazard for landslide, snow avalanche and flood were mapped using inventory maps, susceptibility models, or national regulatory maps (see Tables 1,2 , and 3 for data sources and scales). Through inventory maps we identified areas that are potentially hazardous under the assumption that past events can be reactivated or occur in the future under the same conditions (Varnes, 1984). These data have been integrated with susceptibility zoning for some phenomena that we considered not exhaustively represented in the inventory maps, such as rockfalls and shallow landslides. For rockfalls, we applied a shadow angle approach (Hungr and Evans, 1988; Jaboyedoff and Labiouse, 2003), using $20 \mathrm{~m} \times 20 \mathrm{~m}$ DTM and two different angles for the identification of higher $\left(39^{\circ}\right)$ and lower $\left(33^{\circ}\right)$ hazard zones. For shallow landslides, we applied a coupled slope-stability 
Table 1. Hazard sources and relative scores adopted for landslide risk assessment. See Sect. 6 for scores explanation.

\begin{tabular}{|c|c|c|c|c|c|}
\hline Symbol & Hazard source & Data source & Scale & Ref & Score \\
\hline HRF & Areas susceptible to high-hazard rockfall & Shadow cone model & $1: 10000$ & 1 & 0.40 \\
\hline LRF & Areas susceptible to low-hazard rockfall & Shadow cone model & $1: 10000$ & 1 & 0.30 \\
\hline AL & Active landslide & Inventory map & $1: 10000$ & 2 & 1.00 \\
\hline DL & Dormant landslide & Inventory map & $1: 10000$ & 2 & 0.90 \\
\hline IL & Inactive landslide & Inventory map & $1: 10000$ & 2 & 0.40 \\
\hline $\mathrm{ADF}$ & Active debris flow & Inventory map - buffer $10 \mathrm{~m}$ & $1: 10000$ & 2 & 0.80 \\
\hline DDF & Dormant debris flow & Inventory map - buffer $10 \mathrm{~m}$ & $1: 10000$ & 2 & 0.40 \\
\hline SL & Areas susceptible to rainfall-induced shallow landslide & Slope stability model & $1: 10000$ & 3.4 & 0.20 \\
\hline DSSD & Deep seated gravitational slope deformation & Inventory map & $1: 10000$ & 2 & 0.20 \\
\hline ADL & Active diffused landsliding & Inventory map & $1: 10000$ & 2 & 0.70 \\
\hline DDL & Dormant diffused landsliding & Inventory map & $1: 10000$ & 2 & 0.40 \\
\hline UDL & Unclassified diffused landslides & Inventory map & $1: 10000$ & 2 & 0.55 \\
\hline
\end{tabular}

1: Jaboyedoff and Labiouse, 2003, 2: PROGETTO IFFI, 3: Dietrich and Montgomery, 1998, 4: Crosta and Frattini, 2003.

Table 2. Hazard sources and scores adopted for flood risk assessment. See Sect. 6 for scores explanation.

\begin{tabular}{llllll}
\hline Symbol & Hazard source & Data source & Scale & Ref & Score \\
\hline FA & 80\% of 200 yr flood & Regulatory map & $1: 25000$ & 5 & 1.00 \\
FB & 200 yr flood & Regulatory map & $1: 25000$ & 5 & 0.70 \\
FC & 500 yr flood & Regulatory map & $1: 25000$ & 5 & 0.20 \\
LF & Lacustrine flooding & Historical data and LIDAR analysis & $1: 10000$ & 7 & 0.50 \\
AAF & Active alluvial fan & Inventory map & $1: 10000$ & 2 & 0.80 \\
DAF & Dormant alluvial fan & Inventory map & $1: 10000$ & 2 & 0.20 \\
MiR & River network & Topographic map - buffer 10 m & $1: 10000$ & 8 & 0.60 \\
DBF & Dam-break flooding area & Regulatory map & $1: 10000$ & 9 & 0.10 \\
\hline
\end{tabular}

2: PROGETTO IFFI, 5: PAI, 7: Regione Lombardia, 2007, 8: CTR, 9: CIRC.MIN.LL.PP 352/1987.

and steady-state hydrological model (Dietrich and Montgomery, 1998; Crosta and Frattini, 2003). We used a $20 \mathrm{~m} \times 20 \mathrm{~m}$ DTM, and we parameterized the model considering different combinations of superficial lithology and land use, and assigning parameter values according to the literature and past experiences (Crosta and Frattini, 2003). Both models provide an approximate assessment of susceptibility, but appear to be consistent with the scale and the aim of the analysis, and they have been constrained and calibrated through available event data.

For floods, we adopted hazard zones delimited according to national regulatory maps for both major rivers and 73 dam break scenarios (Table 2).

Data for wildfire risk derive from a Regional database which includes wildfire events occurred in the period 19752005 (SIAB). For each event, the location of initiation point, the affected areal extent, and the damages are available.

For seismic risk, we used the Italian seismic hazard map (MPS working Group, 2004), that expresses the hazard in terms of peak ground acceleration (PGA) with a return period of 475 years (exceedance probability of 0.1 in 50 years).
Table 3. Hazard sources and scores adopted for snow avalanche risk assessment. See Sect. 6 for scores explanation.

\begin{tabular}{llllll}
\hline Symbol & Hazard source & Data source & Scale & Ref & Score \\
\hline SA & Snow avalanche & Inventory map & $1: 10000$ & 6 & 0.5 \\
\hline
\end{tabular}

6: SIRVAL.

Regarding the industrial risk, due to incomplete documentation about the productive processes and the accident scenarios, we considered only explosion-related accidents, neglecting those related to the release of toxic gas and pollutants. Sources of industrial hazard are represented by 246 major risk plants, identified by a national law (D.Lgs. 238/05, according to Seveso Directive 96/82/CE), and mainly located in the plain, in highly urbanised areas. To define a hazard zone, we considered a 1-km radius buffer around the external bordure. This is not fully realistic because it does not account for wind direction and velocity, and other meteorological 
conditions for which not enough data are available. Nevertheless, in defining a buffer of $1 \mathrm{~km}$ we adopted a conservative approach. In fact, most industrial accidents are entirely limited in the plant itself.

Work injury statistics regard accidents occurred to workers regularly registered to INAIL (national insurance for work injuries). Irregular non-insured workers are excluded from the statistics. The database used for work injuries was provided by INAIL and refers to the period 1999-2001. Accidents are classified according to the causes of injures, and their severity.

Road accidents include the ones occurring on different road typologies (i.e. highway, state, municipal, urban and extra urban roads) and involving all types of vehicles. Accidents also include injuries to pedestrians. Road accidents statistics were extracted from the ISTAT database for the 1999-2004 period. A regional traffic model for the main road network was used to normalise road accidents with respect to the expected traffic flux.

As for meteorological risk, due to the lack of complete and homogeneous data, only lightnings were considered, although they represent only a small part of the whole meteorological risk. For the 1996-2005 period, data relative to the number of annual lightnings per $4 \mathrm{~km}^{2}$ cells were provided by the network of the Italian Survey Lightnings System (SIRF-CESI). The network is composed of 16 sensors on the whole Italian territory.

\subsection{Exposed elements}

The identification and mapping of the elements at risk, were conducted with a high spatial accuracy, by using different databases. Human life was not included in the analysis as an independent element at risk. We indirectly accounted for the number of people, potentially involved in dangerous phenomena, by attributing a value of human presence to each class of exposed elements (Table 4), based on the average assumed annual occupancy.

We identified 23 classes of exposed and vulnerable elements, $T_{j}$, and we mapped each element by using different 1:10 000 maps available at a regional scale. Main categories of exposed elements include: residential areas, lifelines, major industrial plants, strategic buildings (schools, hospitals, etc.) and natural resources (Table 4, Fig. 4).

\section{Weighting strategies}

We aggregated the different indicators by applying appropriate weights based on expert knowledge. Case by case, we selected the most convenient weighting strategy (Budgetary Allocation, Fuzzy Sets, and Analytic Hierarchy Process).

Budgetary Allocation is the simplest and more direct way to find weights based on the personal believe. The technique is based on the distribution and allocation of a budget (i.e.,
100 scores in our analysis) over the different indicators (Cardona et al., 2004). It was adopted to assign weights to the indicators of physical risks and aggravating factors due to its capability to manage a large number of variables.

Fuzzy sets (Zadeh, 1965) are useful while attempting to aggregate different dimensions of a complex problem, expressed also in a linguistic way. For each dimension, the linguistic attributes correspond to fuzzy sets with Gaussian membership functions. These are aggregated using the union defuzzification method (Cardona et al., 2004) in order to provide a final score This approach was used to aggregate the different dimensions of the target value scores (Table 4) due to its capability to account for multidimensional linguistic attributes.

Analytic Hierarchy Process (AHP, Saaty, 1990) is a widely used technique for multi-attribute decision making. AHP enables the decomposition of a problem into hierarchy and assures that both qualitative and quantitative aspects of a problem are included in the evaluation process. The opinion about the dominance of risks is systematically extracted by means of pair-wise comparisons. A preference of 1 indicates equality between two indicators while a preference of 9 indicates that one indicator is 9 times larger or more important than the other. The weights are obtained by rescaling between 0 and 1 the eigenvectors relative to the maximum eigenvalue for the matrix of the coefficients, resulting from the pair-wise comparisons. We used this technique for the integration of the different risks, due to its capability to check the internal coherence of the expert's attributions through the calculation of the Consistency Ratio (CR, ranging from 0 to 100). CR values lower than 10 assures an excellent coherence of the attributions (Saaty, 1990).

For Budgetary allocation, Fuzzy logic and AHP, 15 experts from different disciplines were involved. They are:

- five research geologists with expertise on landslide, flood, and avalanche risk,

- three Civil Protection officers responsible for the allocation of economic resources for mitigation projects,

- two environmental researchers working on natural and technological risks,

- five public administrators with expertise in natural and technological risks.

\section{Physical risk indicators}

The physical risk indicator, $R_{P}$, is a dimensionless score expressing the expected direct loss consequent to a hazardous event. According to the intrinsic nature of each threat and data quality and availability, the physical risk has been evaluated at three different levels of complexity. 
Table 4. List of the exposed elements and scores for the different dimensions of value: HL = human life, ENV=environmental, DIR = direct economic, INDIR = indirect economic, MIT = Relevance for mitigation. Map scale 1:10000. See Sect. 6 for scores explanation.

\begin{tabular}{lllllllc}
\hline Exposed elements & ref & HL & ENV & DIR & INDIR & MIT & $\begin{array}{l}\text { Aggregated } \\
\text { fuzzy score }\end{array}$ \\
\hline Continuous residential area & 1 & very high & null & very high & high & moderate & 0.080 \\
Discontinuous residential area & 1 & high & null & high & moderate & moderate & 0.066 \\
Main road & 2 & high & null & moderate & high & high & 0.069 \\
Secondary road & 2 & moderate & null & low & hoderate & moderate & 0.031 \\
Railway line & 2 & high & null & moderate & high & very high & 0.071 \\
Powerline & 2 & null & null & low & high & high & 0.082 \\
Power plant & 3 & null & null & high & high & moderate & 0.067 \\
School & 3 & very high & null & high & low & high & 0.086 \\
Hospital & 3 & very high & null & very high & very high & very high & 0.103 \\
Tourist facility & 3 & low & null & moderate & low & low & 0.029 \\
Sport structure & 1 & low & null & low & low & low & 0.010 \\
Industrial plant & 4 & moderate & null & high & high & null & 0.066 \\
Railway station & 3 & high & null & high & high & high & 0.086 \\
Airport & 3 & high & null & moderate & high & low & 0.067 \\
Industrial area & 1 & high & null & high & high & low & 0.077 \\
Forest & 1 & null & low & low & low & null & 0.002 \\
Coppice & 1 & null & low & low & low & null & 0.001 \\
Bank vegetation & 1 & null & low & null & low & null & 0.000 \\
Pasture & 1 & null & low & null & low & null & 0.000 \\
Natural park & 1 & null & moderate & low & low & null & 0.001 \\
Wooden cultivation & 1 & null & low & low & low & low & 0.002 \\
Sowable land & 1 & null & low & low & low & low & 0.002 \\
Urban park & 1 & low & low & low & low & low & 0.002 \\
\hline & & & & & &
\end{tabular}

1: DUSAF, 2: CTR, 3: MISURC, 4: D.Lgs. 238/05.
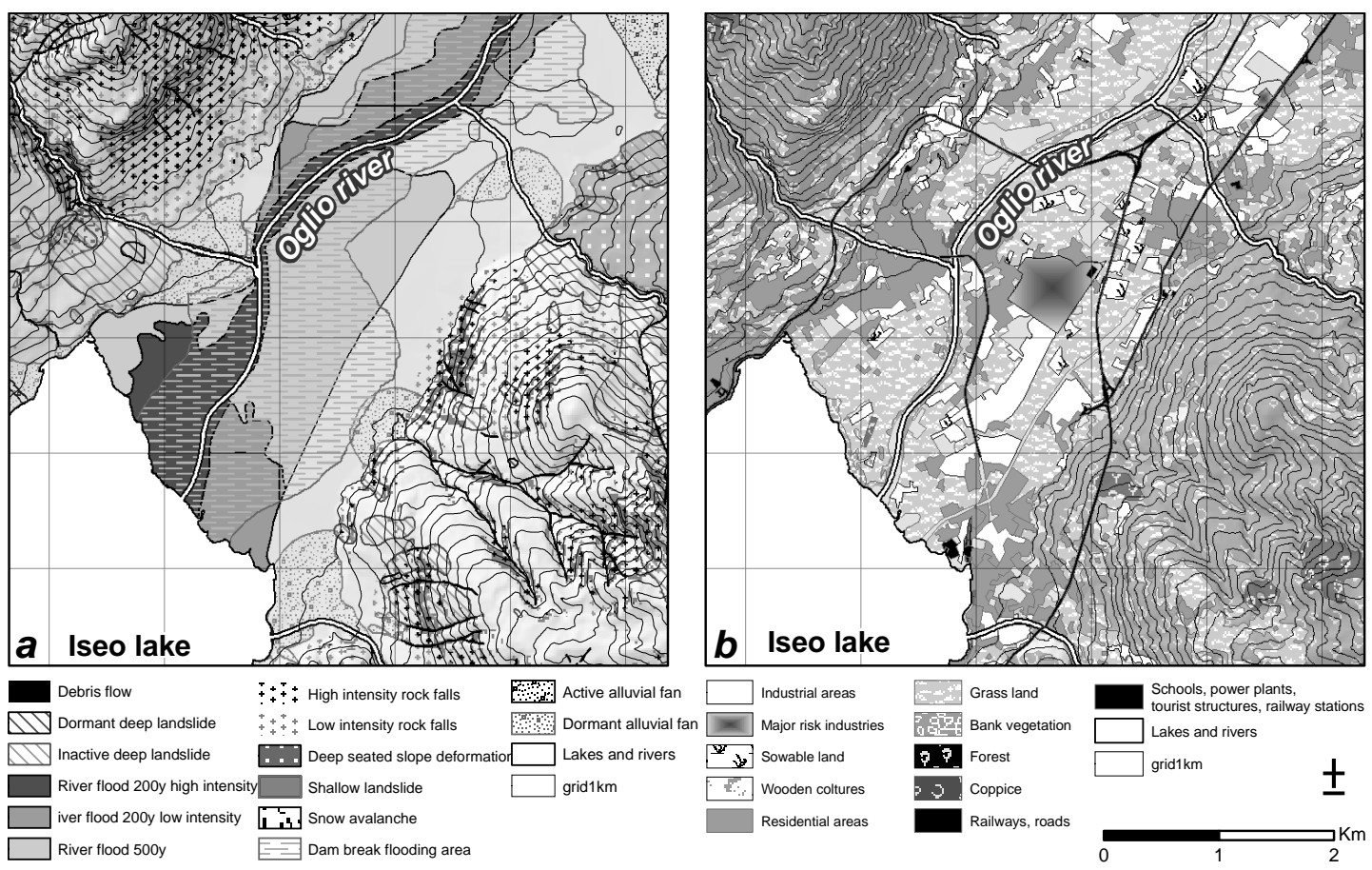

Fig. 4. Sources of hydrogeological hazard (a) and exposed elements (b): example for a selected area (zoom area in Fig. 1). The $1 \mathrm{~km} \times 1 \mathrm{~km}$ square polygons used for the analysis are shown. 


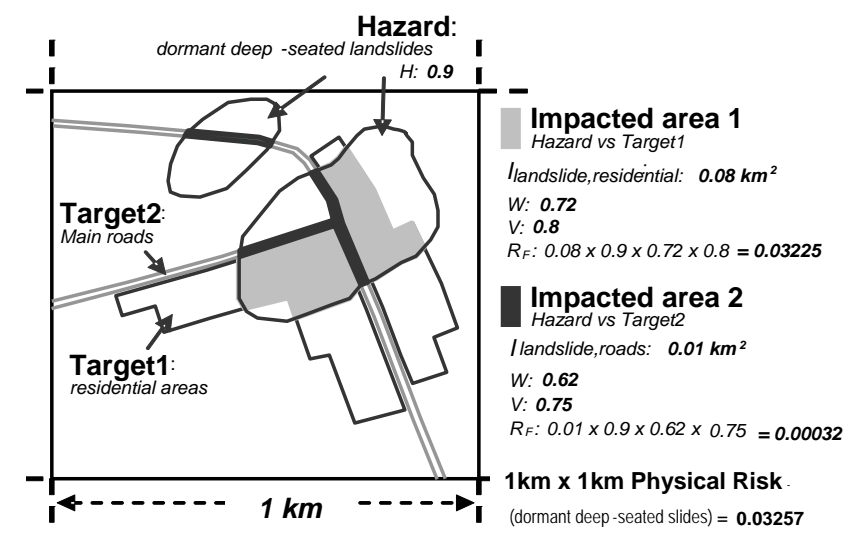

Fig. 5. Example of calculation of physical risk with two impact indicators (i.e. dormant deep-seated landslides impacting on residential areas and roads). The same methodology has been applied for landslide, avalanche, flood, industrial, and seismic risk.

The simplest level of analysis was applied to road accidents, work injuries and lightnings. For these threats, we built sets of indicators based on statistics of available data (PRIM, 2007). The physical risk was calculated as a weighted sum of these indicators.

For landslide, avalanche, flood, industrial and seismic risks, we built impact indicators, $I$. Each indicator is defined as the portion of $1 \mathrm{~km} \times 1 \mathrm{~km}$ cell where a specific target is impacted by a specific hazard (Fig. 5). The physical risk, $R_{P}$, is then calculated as:

$R_{P}=\frac{\sum_{i, j=1}^{N}\left(h_{i} \cdot v_{i, j} \cdot w_{j}\right) I_{i, j}}{\sum_{i, j=1}^{N}\left(h_{i} \cdot v_{i, j} \cdot w_{j}\right)}$

where $h$ is the score for the hazard source $i$ (see Tables 1,2 , and 3), $w$ is the score of the exposed element value $j$ (see Table 4), and $v$ is the score for the vulnerability of the impacted target. The vulnerability score expresses the level of potential damage of each target in response to each hazard.

Due to the large number of scores to be assessed, AHP was not applicable in this case. Scores $h$ and $v$ have been assessed by means of a budgetary allocation method, while the scores $w$ have been obtained through a fuzzy logic approach. The score $w$ expresses a multi-dimensional value accounting for: the economic (direct and indirect) and environmental value, the potential for human losses, and the relevance for mitigation. The economic value was assigned on the basis of regional-averaged economic estimations, without considering site-specific value distribution (e.g., value of buildings according to proximity of city centre). The other value components (e.g., human lives, environmental value, relevance for mitigation) were assigned on the basis of expert knowledge.
For wildfires, a large amount of data was available, and it was possible to develop a scenario-based risk assessment (PRIM, 2007). For each terrain unit, the wild-fire risk was calculated by summing up the product of hazard $H$, vulnerability $V$, and value $W$ :

$R_{P}=\sum_{m=1}^{M} \sum_{n=1}^{N} H_{m} V_{m, n} W_{n}$

where $M$ is the number of wild-fire scenarios and $N$ the number of exposed elements.

In order to allow a comparison of physical risks, we normalized each value by the corresponding regional mean.

\subsection{Hydrogeological risk}

The hydrogeological risk appears to be strongly controlled by the physiographic setting (Fig. 6), and mainly affects mountainous areas, alluvial plains and valley floors, with maximum values along alpine valleys, where flood and landslide risks co-exist with a high urban density. Although this result was expected, it is important to stress that the analysis allowed to quantitatively estimate the risk levels among different terrain units, which is important for the development of mitigation strategies, for the allocation of economic resources, for the planning of new urban areas, and for prioritising the mitigation actions.

To investigate the control of physiographic setting on hydrogeological risk we grouped the terrain units according to the mean elevation in classes of 100 units. For each class, we calculated the mean physical risk for landslide, flood, and snow avalanche (Fig. 7). The maximum landslide risk is reached at $500 \mathrm{~m}$ a.s.l., where the density of exposed urban settlements and infrastructures is higher. The snow avalanche risk is negligible below $1500 \mathrm{~m}$ a.s.l. (Fig. 7a), and is generally low because these processes are common in non urbanised areas (Fig. 7b). The flood risk is very relevant in two different elevation intervals corresponding to either the lower Po plain or the main alpine valleys (e.g. Valtellina), where rivers are not entrenched below the plain level and population density is relatively high.

\subsection{Other risks}

Wildfire hazard was assessed for three reference scenarios of wildfire size (Fig. 8). The choice of the scenarios derives from the regional fire-prevention plan. For each scenario, an exceedance probability was extracted from frequency-size analysis of 2880 events occurred in the 1975-2005 period (Fig. 8).

By means of a discriminant analysis (Klecka, 1980), the wildfire spatial susceptibility was assessed for each land unit as a function of both the previous fire distribution and the predisposing factors (e.g. slope, elevation, aspect, land use, type of vegetation, pirologic potential, river network density, road density). This susceptibility expresses the wildfire potential 


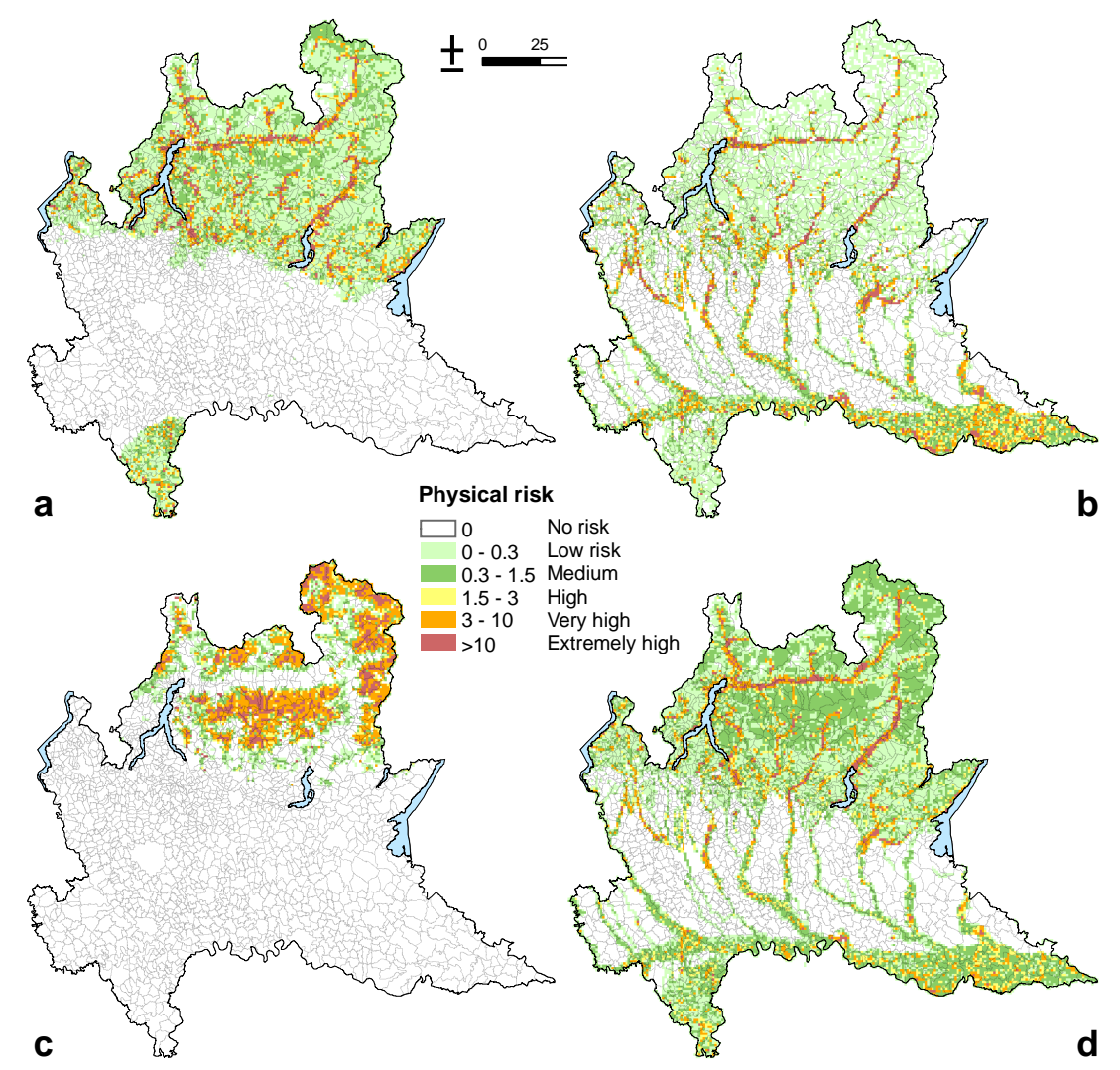

Fig. 6. Landslide (a), flood (b), avalanche (c), and aggregated hydrogeological (d) physical risks, RP. Values of risk are normalized by the regional mean.
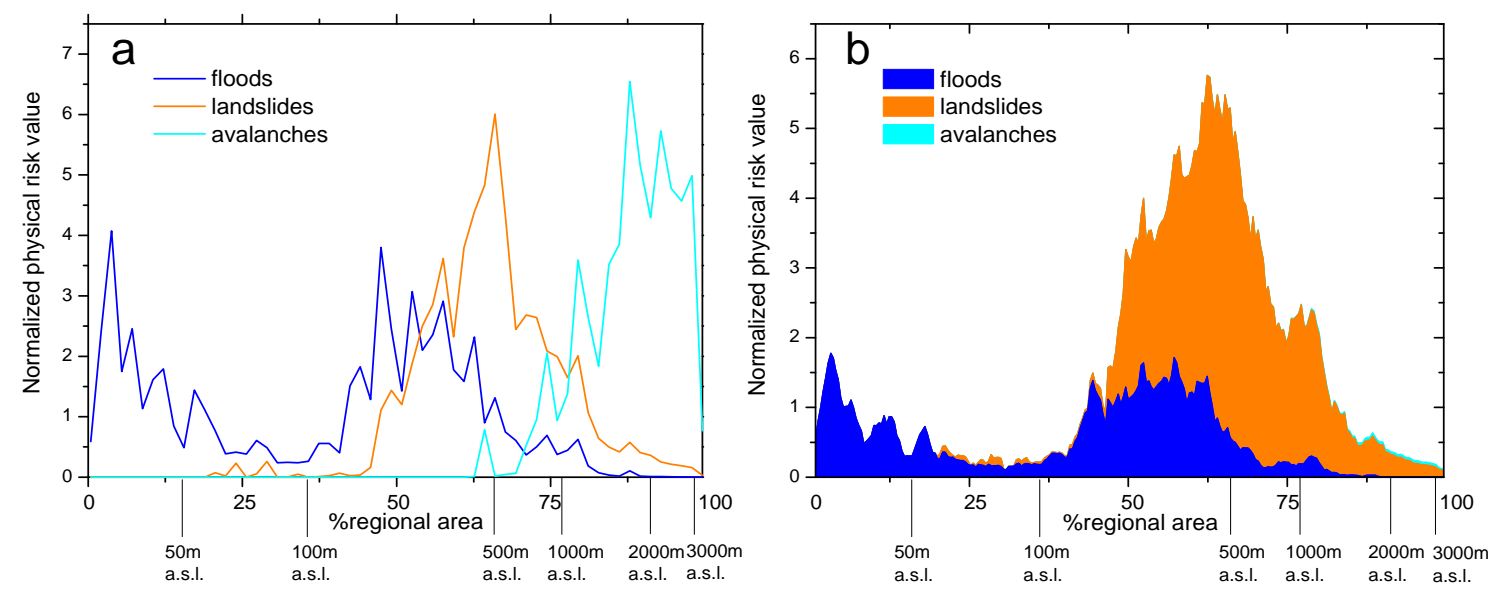

Fig. 7. Flood, landslide, and avalanche physical risk for different elevation quantiles. Risk values are normalised with respect to the regional mean of: (a) each single threat; (b) the hydrogeological physical risk.

for each unit. Hazard was then calculated by multiplying this susceptibility by the regional probability of occurrence of each scenario (Fig. 8). In the assessment of the value of the exposed territory, a great importance has been assigned to the presence of protected natural areas, according to their environmental value (i.e. EU Relevant Places, Special Protection areas, Natural reserves, Natural Parks, National and Regional parks). 


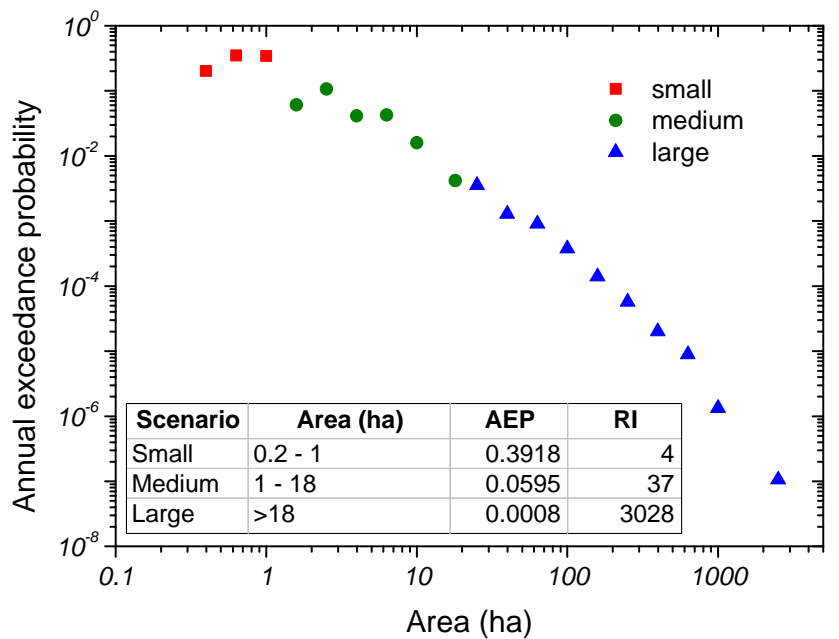

Fig. 8. Wildfire area vs annual exceedance probability, for the three scenarios. Annual exceedance probability (AEP) and recurrence interval (RI) of each scenario are reported in the table. The exceedance probability was calculated from annual frequency (wildfire $n^{\circ} /$ total wildfire $n^{\circ} / 30$ years) of logarithmically binned wildfire areas.

Seismic risk was assessed using the same approach adopted for hydrogeological risk, with the same targets except for buildings, that have been subdivided according to their period of construction (before 1919, between 1920 and 1945, 1946-1961, 1962-1971, 1972-1981, 1982-1991, after 1992), in order to account for different vulnerability.

Industrial risk was assessed by means of impact indicators using the same targets of hydrogeological risk and the $1 \mathrm{~km}$ wide buffer around the plant as source of hazard.

Meteorological risk was assessed using the mean number of annual lightnings for $30 \mathrm{~km} \times 30 \mathrm{~km}$ grid cells (SIRFCESI). Differently from the other threats, this is more a hazard rather than a risk indicator, because it does not include any assessment of the impact on the exposed elements. However, since lightnings are ubiquitous and impacting all exposed elements in an homogeneous way, this limitation should not introduce significant errors in the analysis.

For road accidents, a composite indicator was used, aggregating the number of accidents, the number of injured people and the number of fatalities. These data were analysed for each municipality and for different road typologies (i.e. highway, state, municipal, urban or extra urban road).

For work injuries, the accident rate for different typologies of activity was used as a risk indicator. This rate expresses the possibility of an accident for a given activity at a certain place and in a given time period for a certain number of operators.

For both work injuries and road accidents, the physical risk was assessed by a weighted sum of these indicators. Weights were assigned through budgetary allocation.

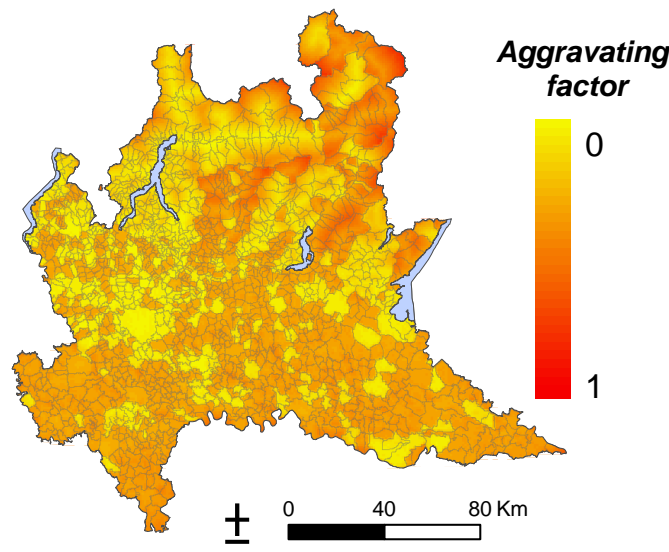

Fig. 9. Map of the aggravating factor, $F$, normalised with respect to the maximum value. Example for the hydrogeological risk.

\section{Aggravating factor}

The aggravating factor, $F$, is an indicator that expresses the lack of coping capacity and resilience of the society, potentially inducing to an aggravation of risk, in terms of indirect costs. It varies from 0 to 1 , under the assumption that it can induce costs amounting to a maximum of $100 \%$ of the physical risk (Cardona, 2004).

$F$ was assessed through a multi-criteria approach based on indicators. For each risk we used the same set of indicators, with different weights (Table 5). The aggravating factor was calculated through the weighted average of the indicators (weights in Table 5), normalized by the maximum value. The effective distances from each cell to emergency management facilities was calculated through a cost distance function, which minimizes the travel time. A budgetary allocation was performed to assign the weights to the 10 indicators with respect to their importance in coping with risks. The aggravating factor was then mapped at a regional scale in $1 \mathrm{~km} \times 1 \mathrm{~km}$ square polygons.

The aggravating factor for the hydrogeological risk is presented (Fig. 9). The factor is null in densely populated regions, where the connectivity is high, the emergency structures are closer, and the civil protection groups can be quickly activated. Due to the presence of civil protection plans and groups, the aggravating factor is low even in some mountain areas with poor connectivity. This behaviour is similar for the aggravating of the other threats.

\section{Total risk assessment}

For each risk, the Total Risk $\left(R_{T}\right)$ indicator was calculated following Cardona et al. (2004):

$R_{T}=R_{P} \cdot(1+F)$

where $R_{P}$ is the Physical Risk, and $F$ is the aggravating factor. 
Table 5. Weights for aggravating factor indicators.

\begin{tabular}{|c|c|c|c|c|c|c|c|}
\hline Indicator & Hydro & Wildfire & Seismic & Meteo & Industr & Road & Work \\
\hline Presence of volunteer civil protection group & 0.01 & 0.02 & 0 & 0 & 0 & 0 & 0 \\
\hline Presence of municipal civil protection group & 0.02 & 0.05 & 0.02 & 0.02 & 0.01 & 0 & 0 \\
\hline Presence of inter-municipal civil protection group & 0.02 & 0.05 & 0.02 & 0.02 & 0.01 & 0 & 0 \\
\hline Distance from closest first aid station (basic equipment) & 0.04 & 0.04 & 0.04 & 0.04 & 0.03 & 0.07 & 0.08 \\
\hline Distance from the closest first aid station (advanced equipment) & 0.06 & 0.05 & 0.06 & 0.06 & 0.05 & 0.11 & 0.12 \\
\hline Distance from the closest fire brigade department & 0.09 & 0.08 & 0.09 & 0.09 & 0.11 & 0.08 & 0.07 \\
\hline Distance from the closest police department & 0.03 & 0.03 & 0.03 & 0.03 & 0.03 & 0.12 & 0.05 \\
\hline Distance from the closest hospital & 0.42 & 0.27 & 0.42 & 0.42 & 0.23 & 0.47 & 0.63 \\
\hline Presence of a municipal civil protection plan & 0.24 & 0.27 & 0.24 & 0.24 & 0.4 & 0 & 0 \\
\hline Interconnection level (number of road network nodes) & 0.03 & 0.12 & 0.03 & 0.03 & 0.1 & 0.12 & 0.03 \\
\hline
\end{tabular}

The spatial pattern of risk seems controlled by different factors depending on the threats.

Wildfire risk is evenly distributed on forested areas, and appears to be independent from the distribution of man-made elements, being the forest itself the principal element at risk (Figs. 10 and 11). It is quite rare, in fact, that other targets (e.g. buildings) are completely surrounded by forests and impacted by wildfires. We also considered that roads are not destroyed or damaged by fire. On the contrary, they are able to break the forest continuity, thus stopping or slowing down the fire propagation, or to favour the intervention.

Seismic risk is mostly present in the eastern part of the Region, where seismic hazard is higher (Figs. 10 and 11), whereas the meteorological risk spreads over the whole study area, with a slight increase in the southern Alps, due to more frequent stormy conditions (Figs. 10 and 11). Industrial risk shows a spot distribution controlled by the location of major risk plants, close to the main cities (Milano, Varese, Bergamo and Brescia) (Figs. 10 and 11). Road accidents and work injuries show a spatial pattern which is largely controlled by the distribution of urbanized areas (Figs. 10 and 11).

\section{Risk integration}

Total risks, $R_{T}$, normalized by their regional mean value, were aggregated into a multi-risk index with AHP which provided a robust set of weights and allowed to evaluate the internal coherence of each expert by means of the Consistency Ratio, (CR) (Saaty, 1990) (Fig. 12, Table 6).

By selecting different subsets of threats, we produced maps of 1) natural risks, including hydrogeological, seismic, wildfire and meteorological risk (Fig. 13a); 2) social accidents, including work injuries and road accidents (Fig. 13b); and 3) na-tech risk including both natural risks and industrial risk; (Fig. 13c), and 4) integrated risk, including all risks (Fig. 14a). In order to analyse the dominance of the threats over the region, we identified for each cell the risk with the highest weighted value (Fig. 14b).
Table 6. Weights associated to each risk typology for the production of the integrated multi-risk map as resulting from AHP analysis.

\begin{tabular}{lrrrr}
\hline Risk & Mean & Median & Std. dev & Range \\
\hline Hydrogeological & 0.16 & 0.15 & 0.05 & 0.12 \\
Wildfire & 0.04 & 0.04 & 0.03 & 0.11 \\
Seismic & 0.06 & 0.05 & 0.03 & 0.11 \\
Meteorological & 0.06 & 0.03 & 0.05 & 0.17 \\
Industrial & 0.10 & 0.10 & 0.05 & 0.18 \\
Road accidents & 0.35 & 0.37 & 0.09 & 0.27 \\
Work injuries & 0.24 & 0.23 & 0.04 & 0.17 \\
Consistency ratio & 14.85 & 11.75 & 6.77 & 20.29 \\
\hline
\end{tabular}

\section{Hot spot identification}

On the basis of the integrated risk map, we finally detected risk hot-spots, defined as contiguous areas that respect the conditions of a minimum number of co-existing threats having a relevant risk level. By changing these conditions we developed three maps characterized by: at least 1 threat with a very high risk value, 10 times the regional mean, or more (Fig. 15a); at least 3 threats with medium risk value, 1.5 times the regional mean, or more (Fig. 15b); at least 2 threats with high risk value, 3 times the regional mean, or more (Fig. 15c).

To delineate the hot-spots we first calculated for each $1 \mathrm{~km} \times 1 \mathrm{~km}$ square polygon the number of risks and their level with respect to the regional mean. Then, we selected all the terrain units satisfying the given set of conditions, and we merged contiguous terrain units into large polygons. Finally, we calculated the area of each polygon, and we reclassified the hot spots according to their size.

In general, high risk hot spots include large urban areas, their main industrialized districts and the main traffic corridors (Milano and its northern neighbourhoods, Bergamo and neighbourhoods, Brescia, Sondrio, Varese), due to the high value of the exposed elements, together with a high 


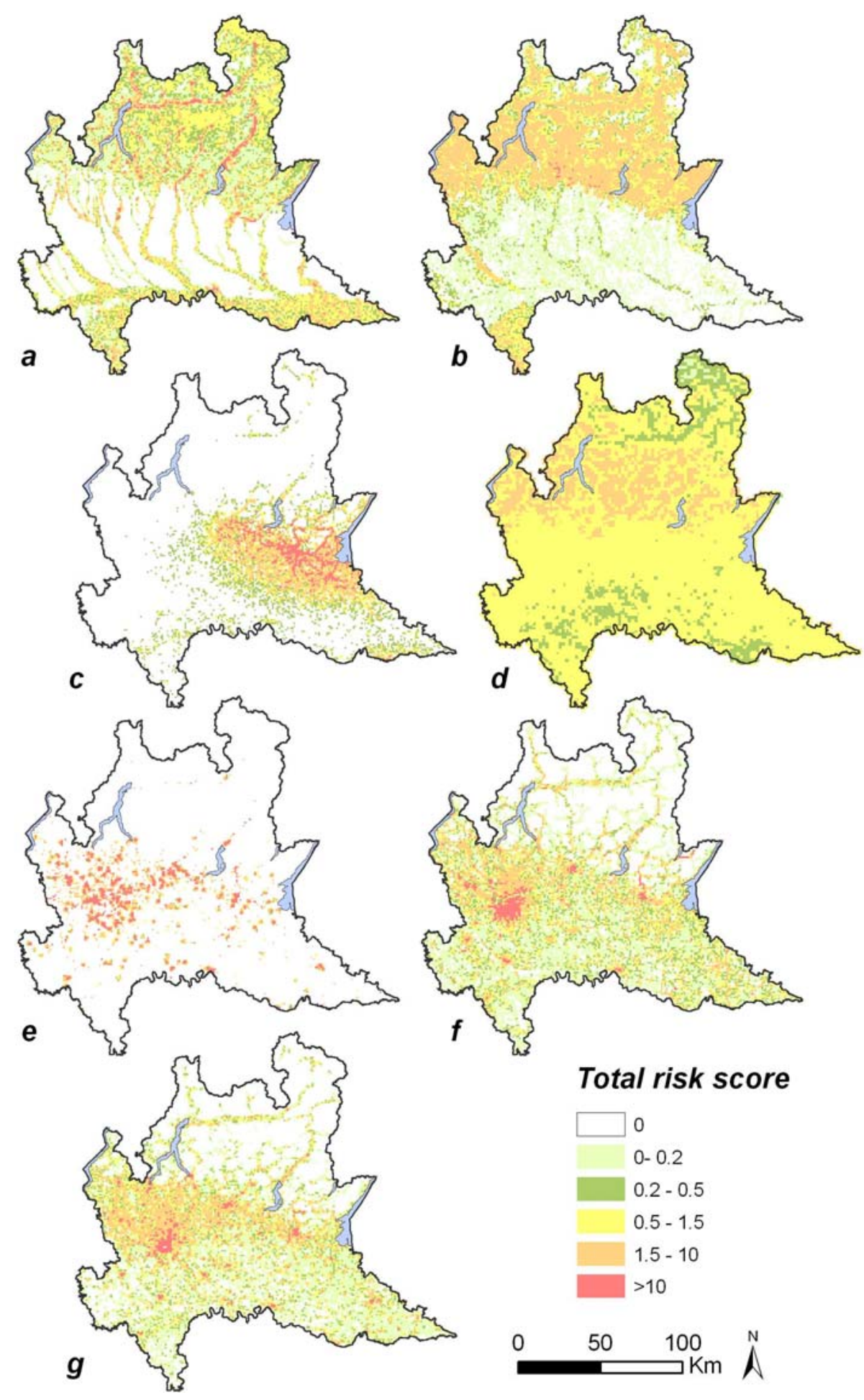

Fig. 10. Maps of normalized total risk, RT, for: hydrogeological risk (a), wildfire (b), seismic (c), meteorological (d), industrial (e), road accidents (f), and work injuries (g). Risk values are expressed with respect to the regional mean. 

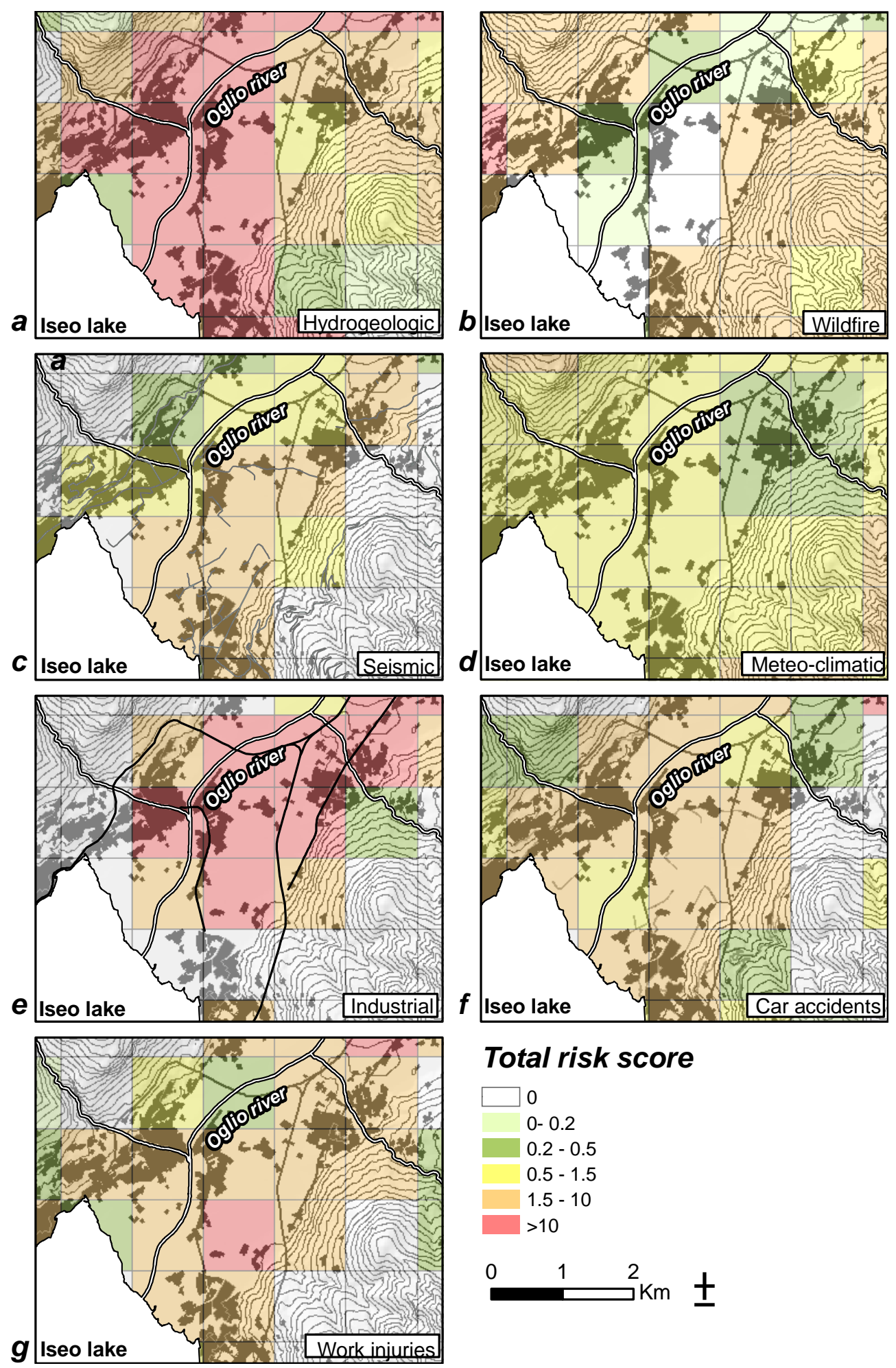

\section{Total risk score}

$\square 0$

$0-0.2$

$0.2-0.5$

$0.5-1.5$

$1.5-10$

$>10$

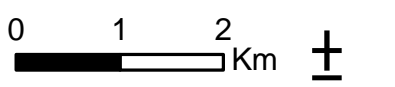

Fig. 11. Normalized total risks, RT, for a specific area (see Fig. 1): hydrogeological risk (a), wildfire (b), seismic (c), meteorological (d), industrial (e), road accidents (f), and work injuries (g). Risk values are expressed with respect to the regional mean. 


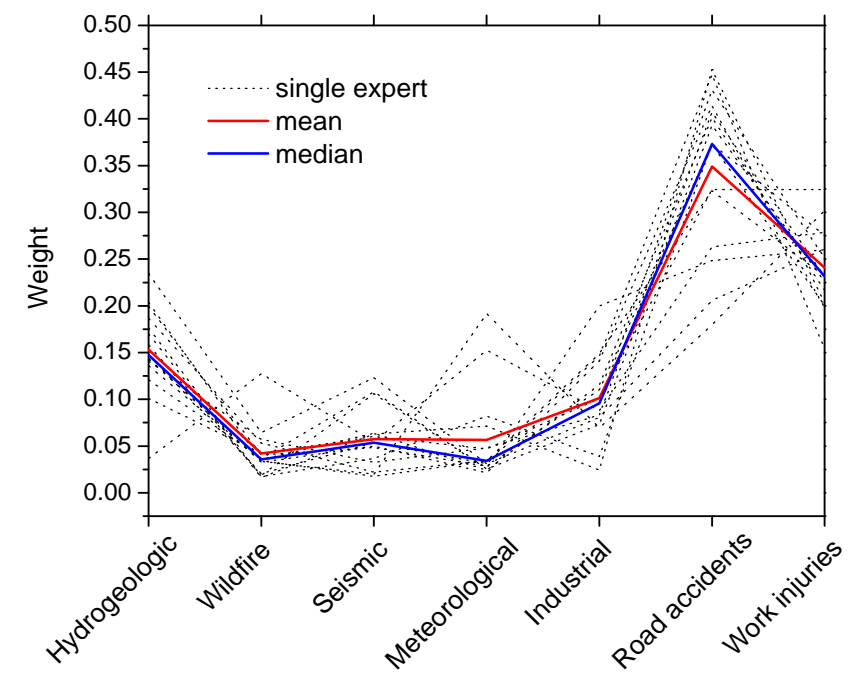

Fig. 12. Risk weights attributed by each of the 15 members of the technical panel, by means of the AHP method.

number of road accidents and work injuries. When considering the co-existence of different threats with lower risk values (Fig. 15b and c), hot-spots appear also in rural areas in Valtellina, in the northern area of the Milano province, in the prealpine valleys into the north of Brescia and Bergamo, and in the low Po plain.

The analysis of the percentage of square polygons with more than a certain number of threats (Fig. 16) shows that many cells are affected by more than one threat, especially for moderate risk level (e.g., $40 \%$ of cells have more than 2 risks exceeding level 1). This suggests that the coexistence of threats in Lombardy is significant, thus justifying the analysis of the risks in an holistic way. Large areas and many people are threatened by various risks that do not reach high levels, but can interact to originate complex or domino effects. In order to develop an efficient mitigation strategy, the coexistence of them must be taken into account.

\section{Sensitivity analysis}

Due to the uncertainties associated to the weighting of the indicators, we decided to perform a sensitivity analysis to evaluate the variation of outputs to small changes in the weight. As example, we present the sensitivity analysis related to: 1) the scores of hazards and exposed elements for hydrogeological physical risk, 2) the weights of aggravating indicators of hydrogeological risk, and 3) the weights of all different threats for their aggregation.

The hydrogeological physical risk is linearly correlated to the variation of both hazard sources and target scores. The sensitivity is higher for variables characterised by high scores, and large spatial diffusion (e.g., 500 years flood, Fig. 17; discontinuous residential areas, Fig. 18). For the
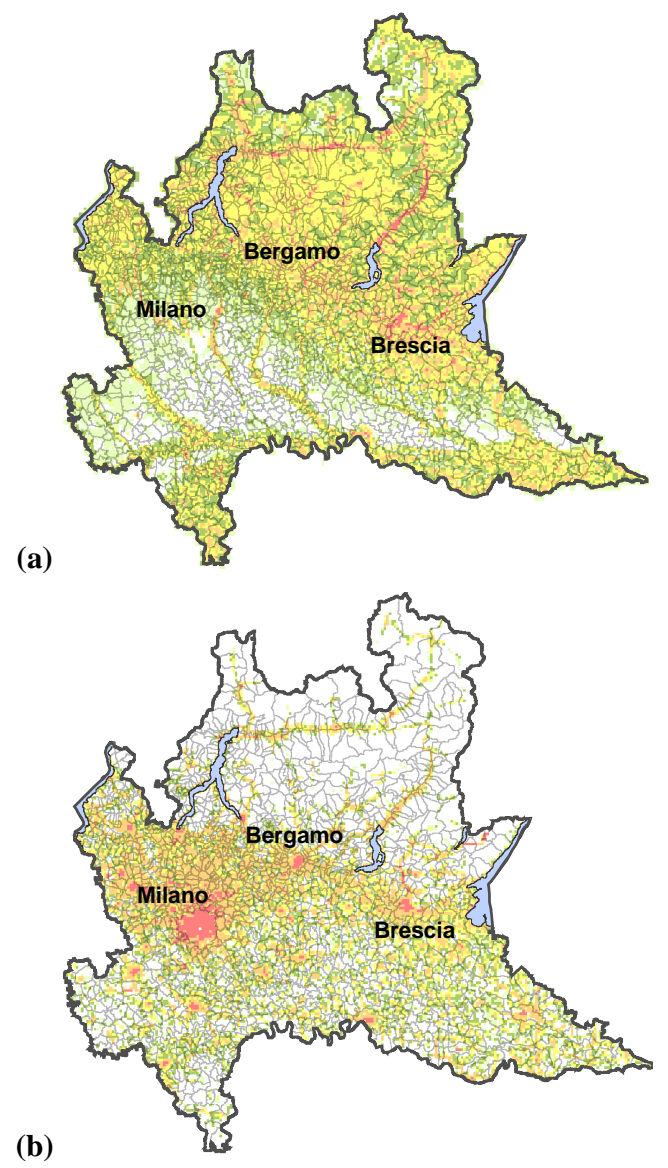

(b)

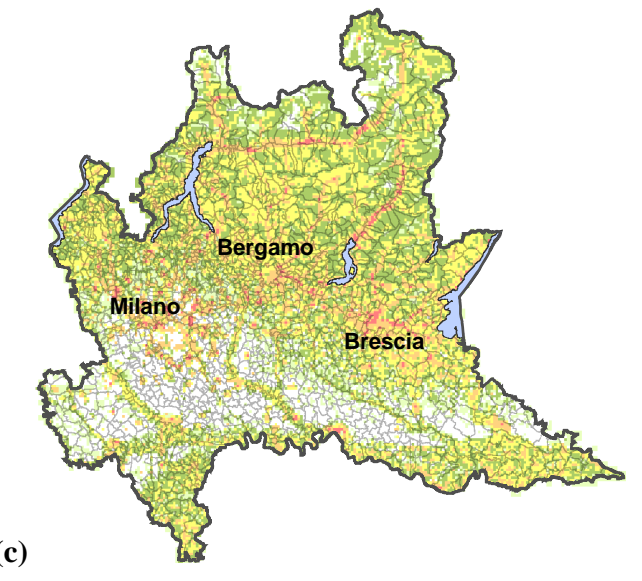

Integrated risk

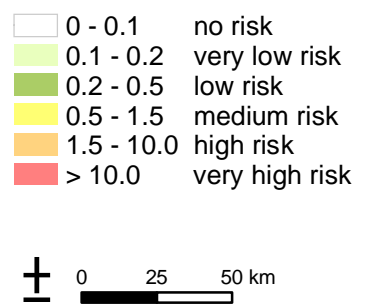

Fig. 13. Integrated risk maps normalized with respect to mean regional value, by expert weighting, for (a) natural risks, (b) road, and work accidents. (c) Na-tech risks (hydrogeological, seismic, wildfire, meteorological and industrial risks). 


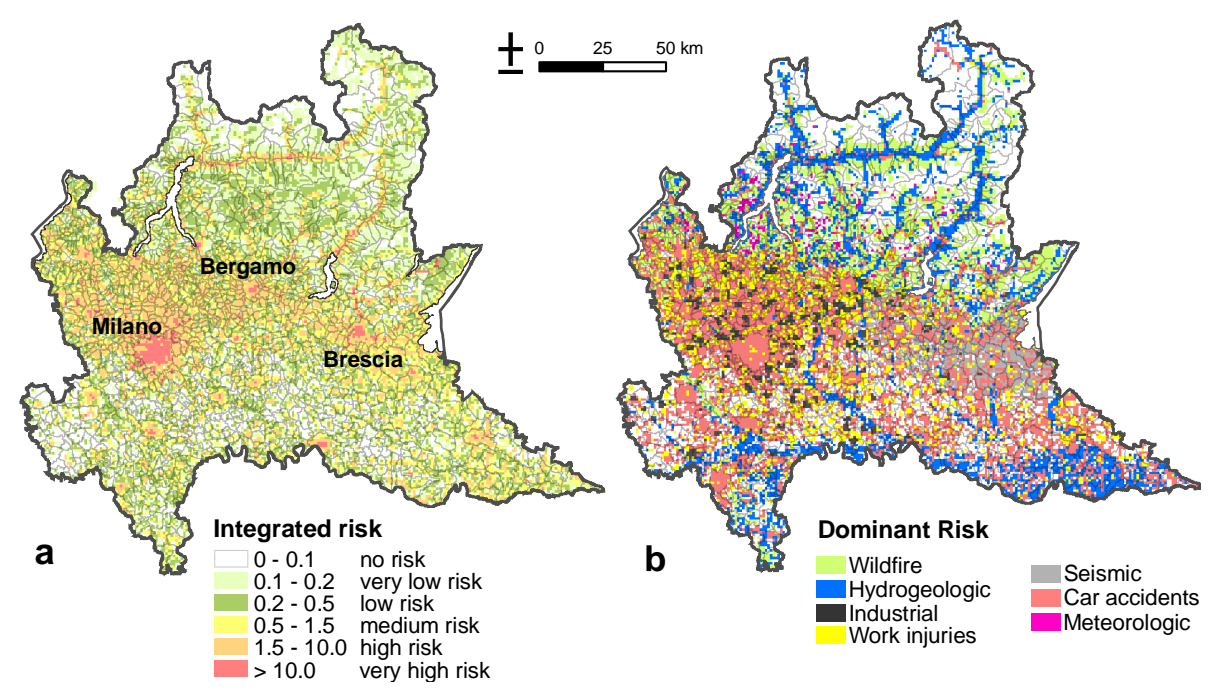

Fig. 14. (a) Integrated risk map of all the considered threats by expert weighting, normalized with respect to mean regional value. (b) Dominant risk map, for risk values $>0.05$.

(a)

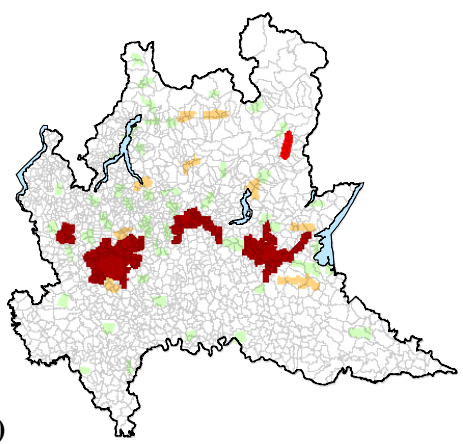

(b)

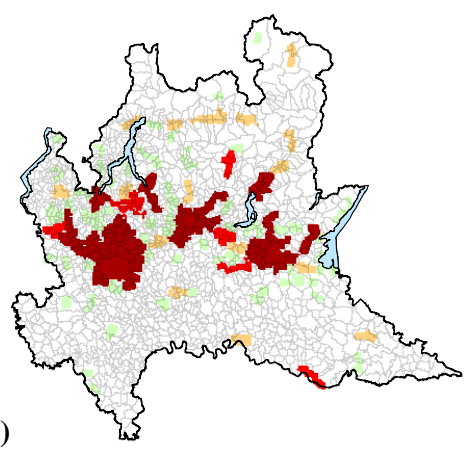

(c)

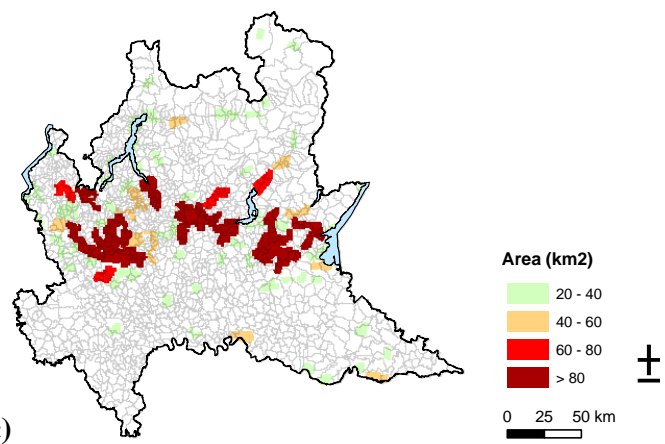

Fig. 15. Hot spot risk areas, delimited by the number and relevance of coexisting risks, reclassified according to the size of the contiguous area: (a) at least one threat with very high risk (10 times the regional mean); (b) two threats with high risk ( 3 times the regional mean); (c) three threats with medium risk (1.5 times the regional mean).

aggravating factor, $F$, the most sensitive indicators are the presence of a civil protection plan and the distance from hospitals (Fig. 19). For the integration of risks (Fig. 20), the slope of the trend line simply corresponds to the weight of each threat, since the integrated risk is a weighted mean of the total risks. Hence, a percent variation in the larger weight causes larger variations in the integrated risk.

\section{Discussion}

The generation of multi-risk maps is a complex task that has been tackled in this paper. The first step of the analysis consists in the identification and mapping of the hazard sources. This step can present some difficulties related to: the data spatial resolution (especially for landslides, work injuries, lightnings, road accidents), the temporal window covered by the databases (e.g. work injuries, road accidents), the difficulty in defining the area of influence of some hazards

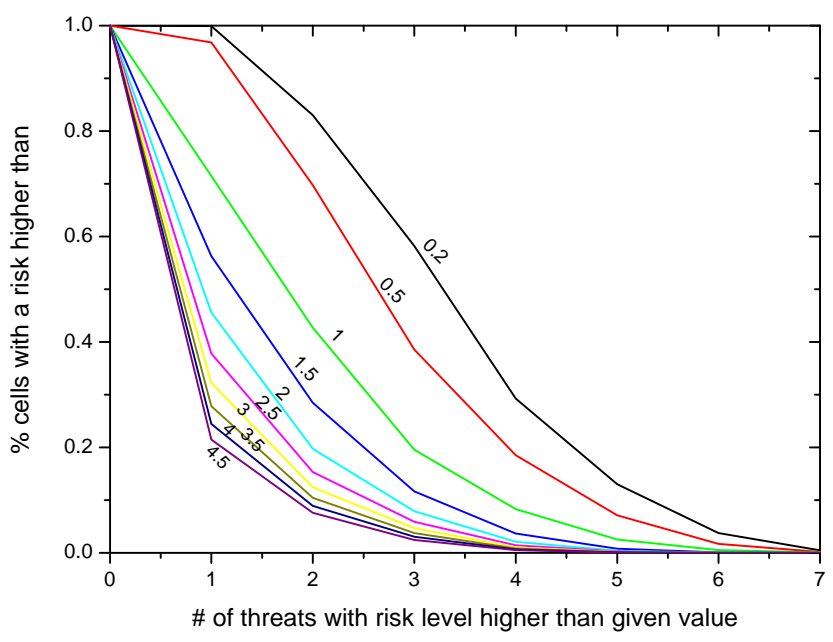

Fig. 16. Percentage of cells affected by a number of risks exceeding a certain risk level (normalized by the regional mean). 

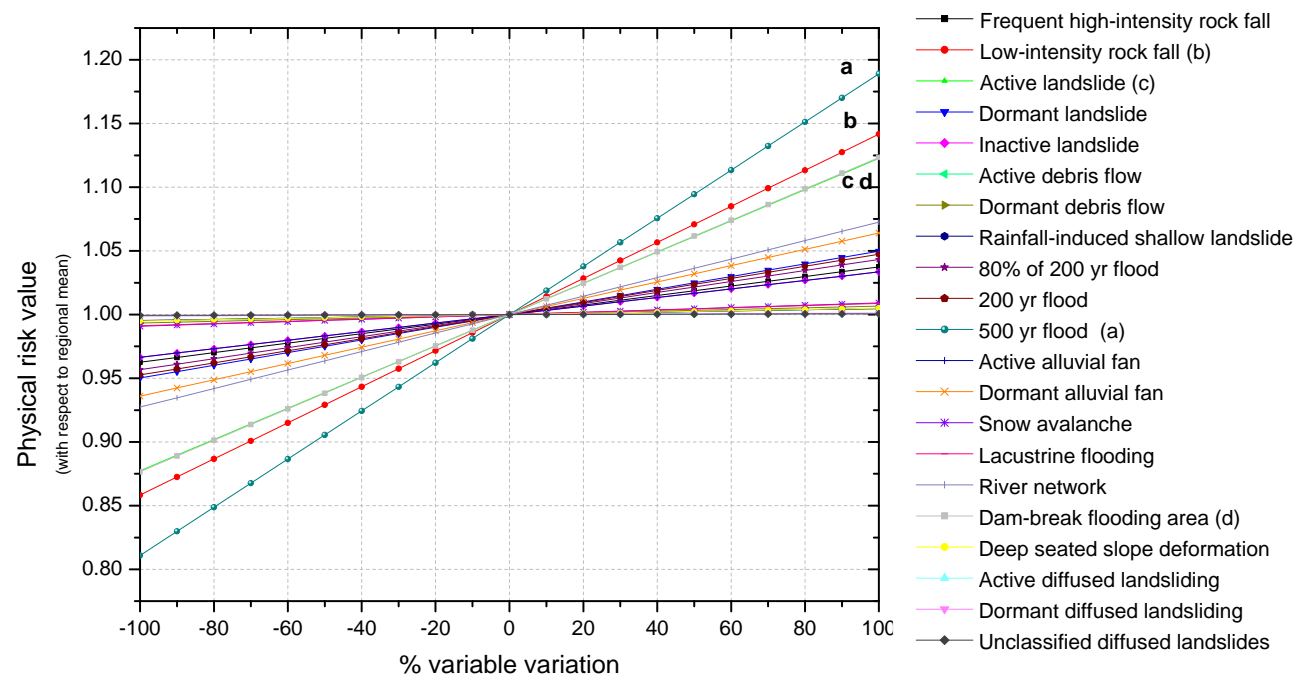

Fig. 17. Sensitivity analysis for hazard sources scores. See legends for reference of letters a, b, c, and d.

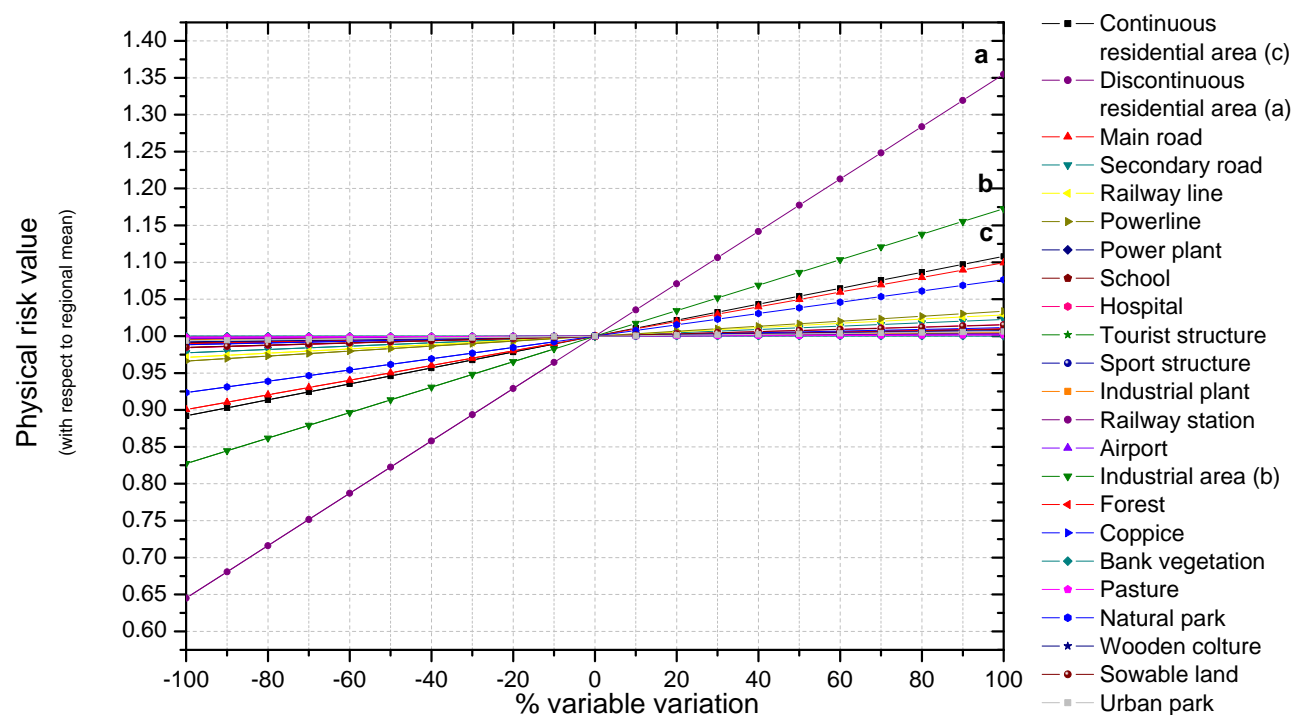

Fig. 18. Sensitivity analysis for target value scores See legends for reference of letters a, b, c, and d.

(e.g., industrial accidents, wildfires), the availability of data for some risks (e.g. meteorological, industrial), for which we needed to limit our analysis to a sub-set of specific phenomena. As a consequence, the hazard sources are characterized with different accuracy and homogeneity, thus hampering the use of more rigorous methods (e.g., Probabilistic Risk assessment, PRA).

Weighting of indicators is a step that may introduce uncertainty. On a case by case approach, we select different techniques to reduce this uncertainty, all based on expert knowledge: fuzzy logic was used to aggregate different dimensions of value, while AHP was used when the number of considered variables was limited. Otherwise, the use of AHP would have been too complex and time costly. This forced us to perform a simpler budgetary allocation. Evaluating the un- certainty and its propagation in risk assessment is not simple at this scale of analysis, and feasible only for more detailed studies (Lari, 2009).

However, due to these uncertainties, we adopted a conservative approach, by always considering the worst possible case. This was done both in the identification and mapping of hazard scenarios, and in the evaluation of the aggravating factors.

With respect to previous multi-risk assessment studies, our methodology allows a higher spatial resolution. We preserve the spatial detail of local scale studies (Cardona and Hurtado, 2000; Masure, 2003; Cardona, 2001; Barbat and Cardona, 2003) within a regional scale analysis, also considering different risks as in ESPON (2005) and UNDR/HOT SPOT projects (Dilley et al., 2005). 


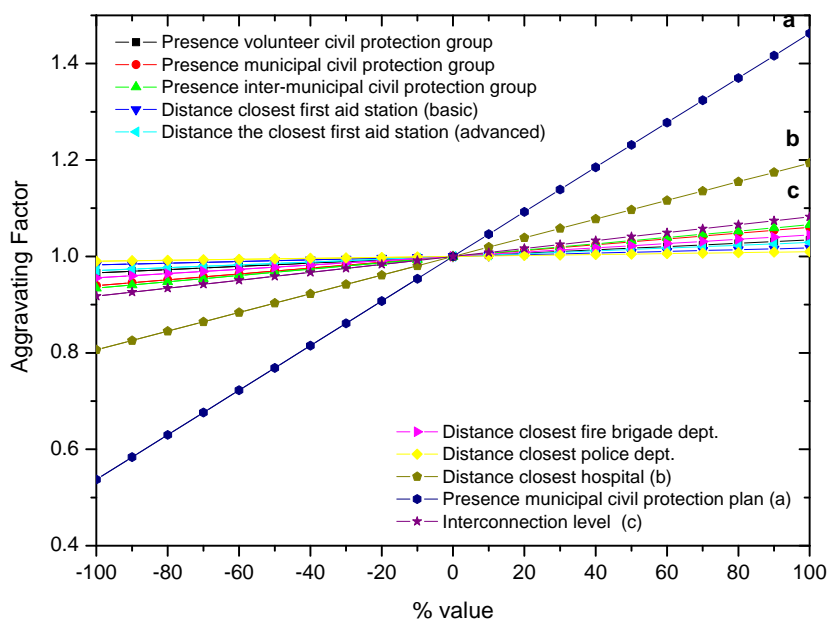

Fig. 19. Sensitivity analysis for aggravating factor for hydrogeological risk. See legends for reference of letters a, b, and c.

\subsection{Spatial pattern of risk}

The spatial pattern of different risks in Lombardy is governed by the distribution of either the hazards or the exposed elements: the first case is common for risks related to larger and infrequent events (hydrogeological, seismic, wildfire, and industrial risks), whereas the second is common for frequent, and evenly distributed events (road accidents and work injuries).

The spatial distribution of different threats in Lombardy is strongly controlled by the physiographic setting (e.g. landslides, avalanches), as results from the analysis of normalised total risk for all the municipalities located in plain, hilly, or mountainous areas, according to ISTAT (National Institute of statistics) classification (Fig. 21). To refine this analysis, we also grouped the terrain units according to the mean elevation in classes of 100 units, and we analysed the risk of each threat within all the elevation classes (Fig. 22).

The area below 100 ma.s.l., which occupy almost $35 \%$ of Lombardy, is characterised by a overall low risk level. This is a rural area, with a relatively low population density, scarce industrial activities, and with dominant threats related to road accidents, hydrogeological risk in the flooding area of the Po river, and a few localised industrial risks and work injuries (e.g. Cremona area).

The area between 100 and $200 \mathrm{~m}$ a.s.l. (almost $15 \%$ of the territory) shows the highest risk value. This includes the most populated zones (e.g., Milano and Brescia), and is affected by severe threats related to human activities (industrial risk, road accidents and work injuries) and to seismic risk (Brescia). Considering weighted risks, a strong dominance of road accidents is observed (Fig. 22).

In the area between 200 and 500 ma.s.l. (almost $15 \%$ of the territory), we observe a decrease of the overall risk level, linked to a decrease of population density and economic

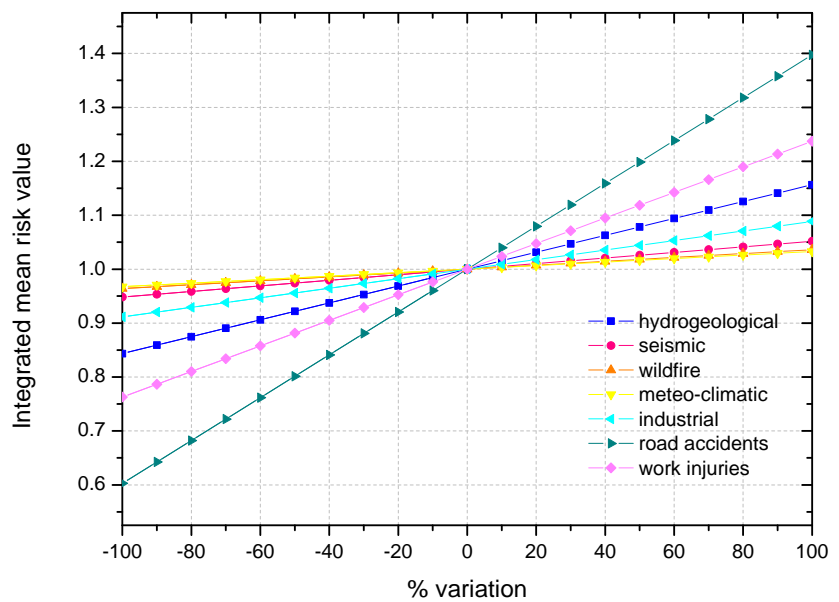

Fig. 20. Sensitivity analysis for threat weights.
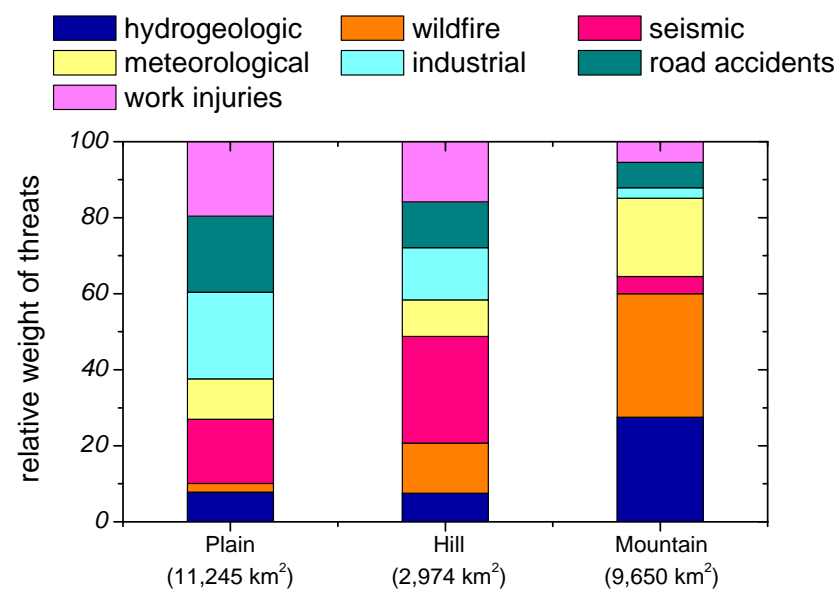

Fig. 21. Total risks relevance for municipalities classified according to the physiographic setting.

activities. The dominant threats change progressively from technological to natural (landslide, wildfire) with the exception of seismic risk, which is independent from altitude. Above $500 \mathrm{~m}$ a.s.l. (almost $35 \%$ of the area), the risk level decreases because of the scarcity of human-related exposed elements. In this area the meteorological threat appears to be dominant, merely because other risks are absent. Road accidents in mountain areas are locally relevant (e.g. higher Valtellina, Fig. 19c) along strategic transnational roads (Fig. 22).

In order to observe the relations with the population density, we calculated the mean physical risk value for each municipality (Fig. 23). Work and road accidents are linearly correlated with population density: these threats are diffused on the whole study area, and then controlled by the spatial distribution of the elements at risk, i.e. people.

Industrial and seismic risks appear to be mostly influenced by the distribution of the hazard sources: spot-like in the first case, diffused but increasing towards north-east in the second. 

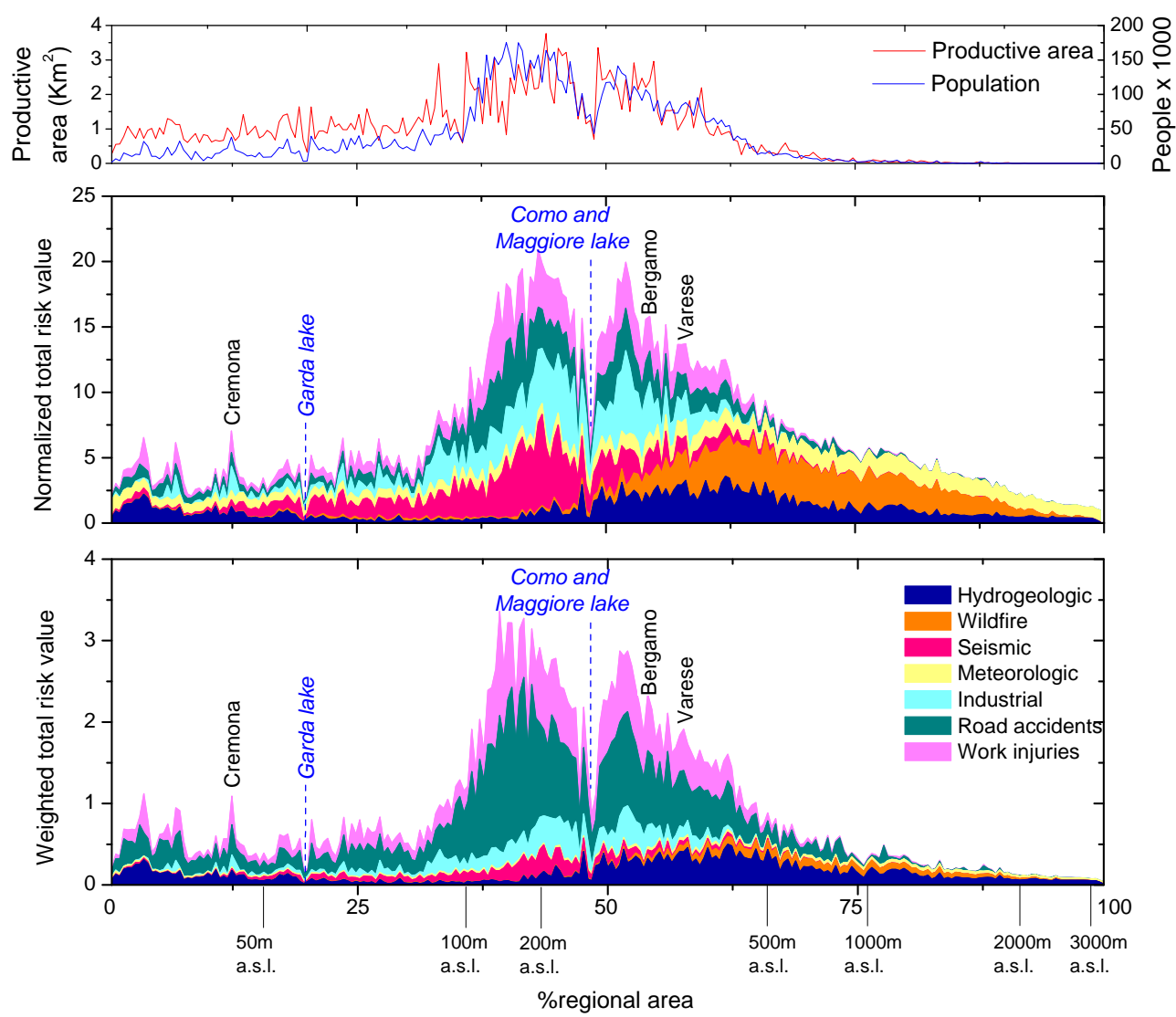

Fig. 22. Relevance of each total risk for different elevation quantile classes: (a) distribution of population and productive activities, (b) normalised superimposed risk values with respect to the regional mean, (c) superimposed risk values weighted according to expert AHP weighting (Fig. 24).

Wildfire and hydrogeological risks do not show a clear correlation with the population density: being relatively localised, they affect only some towns of the area, generally in the mountainous part and characterised by low population density (e.g. Sondrio).

\subsection{Influence of risk perception on weighting process}

As mentioned above, the weighting process is intrinsically subjective. For this reason, the results can be conditioned by the individual attitude or point of view of stakeholders, inhabitants and experts involved in weighting. In order to further investigate this issue, we performed a simple Budgetary Allocation considering four possible alternatives: expert opinion, risk averse attitude, social perception, and political perception. In Fig. 24, we show the relative averaged weights assigned to each threat from the different perspectives.

Weights obtained through Budgetary Allocation differ from those derived by the AHP method. The AHP weights show a stronger importance of road accidents and work injuries, that together amount to $60 \%$ of the total. In the Budgetary Allocation method, the attribution of the weights is direct; this can lead single experts to be reluctant and more cautious in attributing strongly unbalanced weights.

Risk aversion is an attitude to risk where relatively frequent small accidents are more easily accepted than one single rare accident with large consequences, although the total expected losses are equal in both cases. In our case, industrial and seismic risks, which can potentially have catastrophic consequences, are perceived to be more severe than road accidents and work injuries (Fig. 24).

The social perception is considered as the perception of common non-expert people who accept more easily voluntary rather than non-voluntary risks, and who consider more critical those risks that could be potentially controlled by the public administrator through defensive works, regulations and other mitigation strategies. In our analysis, this implies that a typical risk related to single behaviour, such as road accident, is perceived as less important, and seismic risk is also under-estimated because fatalistically perceived as uncontrollable (Fig. 24).

Finally, the political perception is strongly conditioned by the public administration objectives and by the management duties: a strong importance is given to the threats related to human activities or to planning strategies (Fig. 24). 


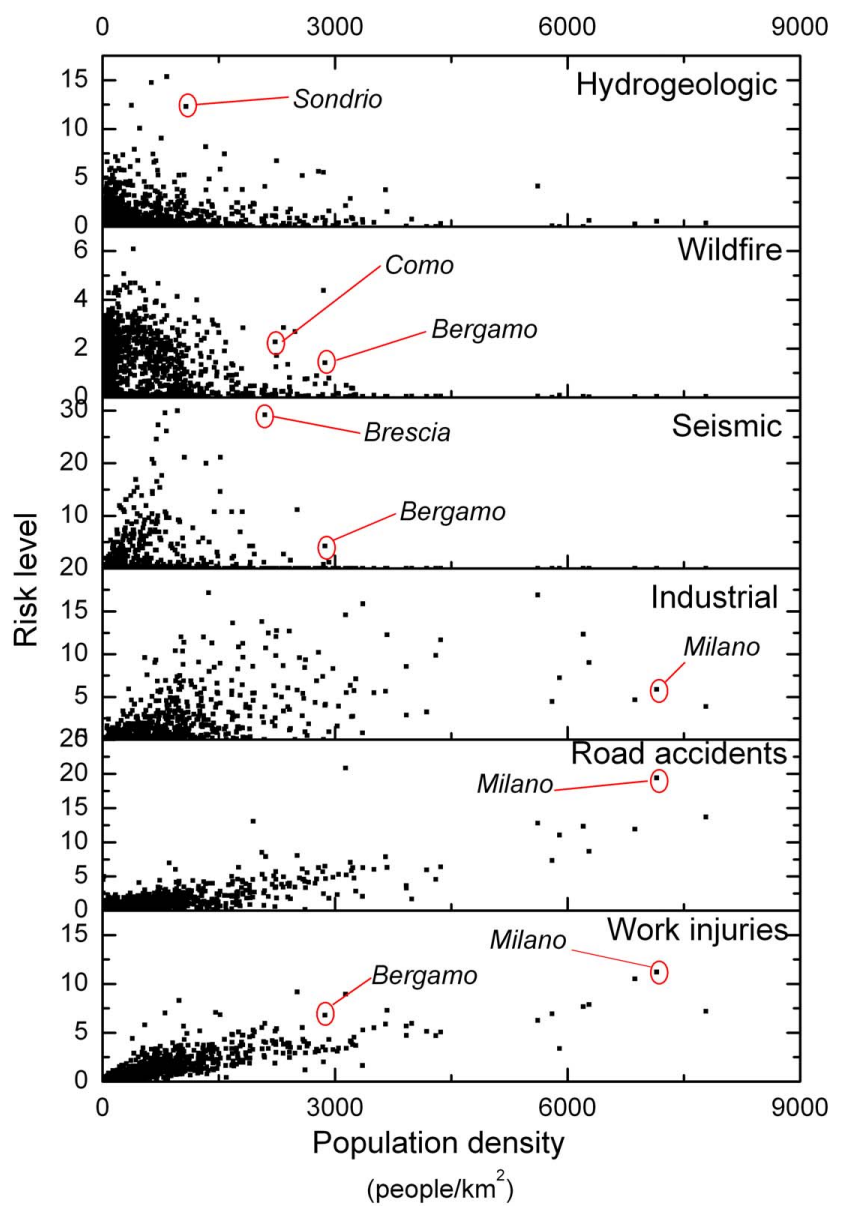

Fig. 23. Averaged level of risk (normalised by the regional mean) with respect to the population density of each municipality.

\subsection{High risk/hot-spot areas}

Within a multi-risk framework, the criticality of an area depends on: 1) the number of interacting risks that co-exist at the same place, and 2) the level of each risk (a lonely risk, if acute, can be problematic and conditioning for land planning and development). On the basis of these criteria, we detected contiguous areas representing risk "hot spots". We propose three possible scenarios for the identification of hot spot areas. The first scenario highlights areas with maximum risk level, but does not account for the co-existence of risks. The other scenarios consider the simultaneous presence of more than one risk. Since this is a predisposing factor for domino effects and interactions that can increase the criticality of an area, for example by increasing the aggravating factor (destruction of facilities, roads, infrastructures), the second and third scenarios look preferable (Fig. 15). The choice among these two scenarios depends on the characteristics of the territory, and the complexity of the interactions among different processes.

The extent of the "hot-spots" can be important for land planning, for development and prioritisation of mitigation

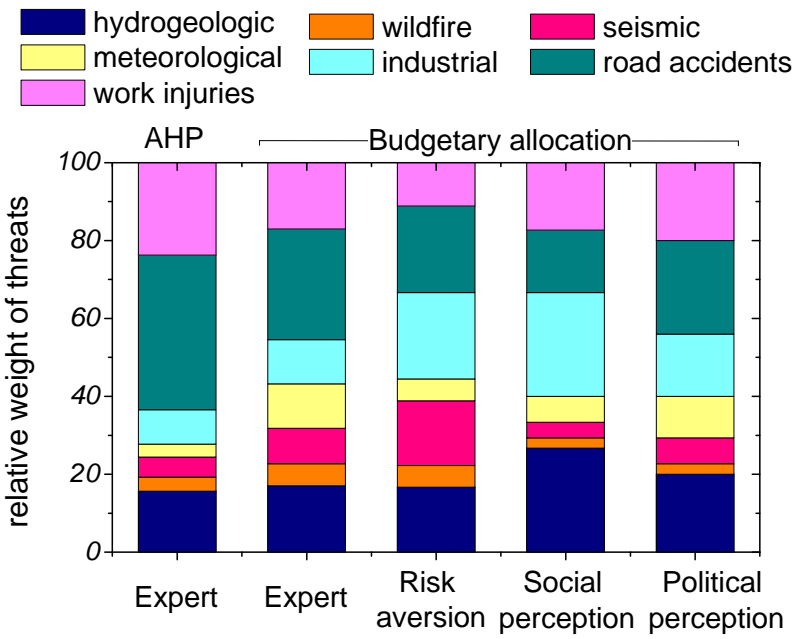

Fig. 24. Different risk weights as obtained through various expert panels (technical, political, social, and risk averse).

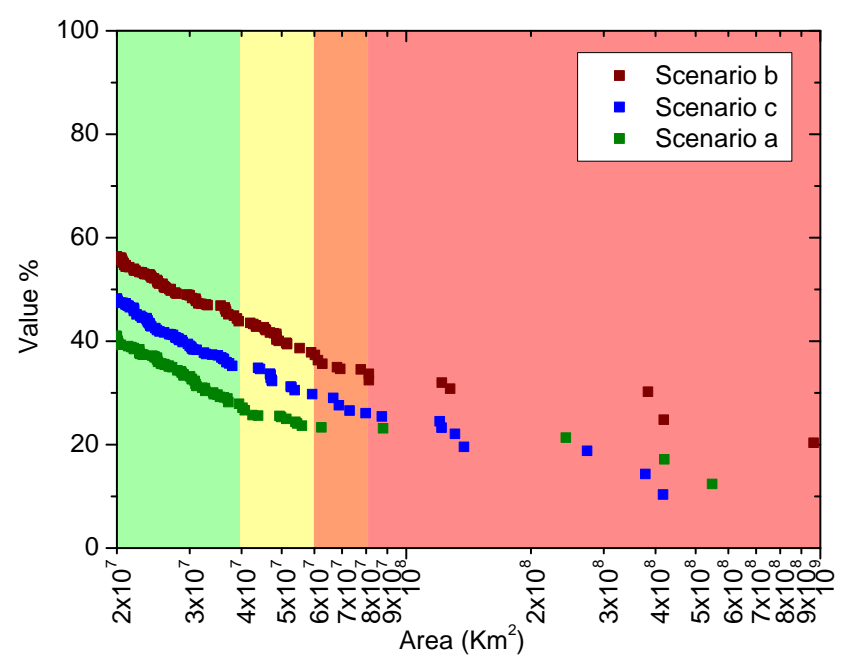

Fig. 25. Plot of the percentage of total exposed value for each hot spot and for the three scenarios (cf. Fig. 15) with respect to the extent of the area. Colours indicate classification of area extents as in Fig. 15.

strategies. Large "hot spots" are more critical for risk management because they include large and complex socioeconomic systems with potentially strategic infrastructures and services. The larger the "hot-spot", the larger the external area of influence that can be potentially affected in case of a system breakdown.

We observe that only few large "hot spots" (Fig. 25) affect high percentages of the total exposed value: the three largest areas include $30 \%$ (scenario b), $22 \%$ (scenario c), $19 \%$ of the regional value (scenario a) and most of the population (see Table 7). For this reason, some actions focused on these areas could be significant to control a large part of the regional criticalities. This underlines the relevance of these results in developing a risk mitigation and management policy. 
Table 7. Hot-spot risk areas, extension and exposed value.

\begin{tabular}{lllllllll}
\hline scenari & \# threats & risk level & $\begin{array}{l}\text { hot spot } \\
\text { area } \\
\left(\mathrm{km}^{2}\right)\end{array}$ & population & $\begin{array}{l}\text { residential } \\
\text { area } \\
\left(\mathrm{km}^{2}\right)\end{array}$ & $\begin{array}{l}\text { productive } \\
\text { area } \\
\left(\mathrm{km}^{2}\right)\end{array}$ & $\begin{array}{l}\text { \% regional } \\
\text { area }\end{array}$ & $\begin{array}{l}\text { \% value exposed } \\
\text { elements }\end{array}$ \\
\hline $\mathrm{a}$ & at least 1 & very high & 3264 & 5300516 & 620.4 & 284.8 & 14 & 40 \\
$\mathrm{~b}$ & at least 2 & high & 5228 & 6637056 & 911.3 & 384.2 & 21.9 & 56 \\
$\mathrm{c}$ & at least 3 & medium & 4164 & 5866495 & 778.4 & 327.9 & 17.4 & 48 \\
\hline
\end{tabular}

\section{Conclusions}

Combining risks with different characteristics, metrics and distributions is extremely difficult, but it is useful for some public administrations, which have to manage and plan mitigation strategies not only on critical situations deriving from a single specific risk, but on the territory in its complexity considering the interaction between threats, processes, and dynamics.

Presently, the Lombardy region lacks the conditions for a fully quantitative, probabilistic multi-risk analysis, because of heterogeneity in data quality and availability. For this reason, only an indicator based approach was possible at the scale of the analysis. For the same reason we adopted $1 \mathrm{~km} \times 1 \mathrm{~km}$ terrain units, that can be considered reasonable with the current data availability and scale of the analysis.

Although the analysis is perfectible, it allows the detection of integrated risk areas and "hot-spot" areas useful for decision making and prevention policies, and for the realisation of integrated area management plans.

Acknowledgements. Thanks to: Raffaele Raja, Andrea Zaccone, Massimo Ceriani, Francesco Pozza (Regione Lombardia); Bruna Comini, Elena Gagliazzi and Giacomo Borromeo (ERSAF) for analysis wild-fire risk; Stefano Oliveri (CRASL) and Giuseppe Triacchini (JRC) for analysis of road accidents and work injuries; Elena Valbuzzi and Fabio Corgiat (Università degli Studi di Milano Bicocca).

Edited by: F. Guzzetti

Reviewed by: J.-P. Malet and another anonymous referee

\section{References}

Agliardi, F., Crosta, G. B., and Frattini, P.: Integrating rockfall risk assessment and countermeasure design by $3 \mathrm{D}$ modelling techniques, Nat. Hazards Earth Syst. Sci., 9, 1059-1073, 2009, http://www.nat-hazards-earth-syst-sci.net/9/1059/2009/.

AVI - Aree Vulnerate Italiane da frane ed inondazioni, available at: http://avi.gndci.cnr.it, last access: April 2007.

Baecher, G. B. and Christian, J. T.: Reliability and statistics in Geotechnical engineering, Wiley \& sons, 2003.

Barbat, A. H. and Cardona, O. D.: Vulnerability and disaster risk indices from engineering perspective and holistic approach to con- sider hard and soft variables at urban level, IDB/IDEA Program on Indicators for Disaster Risk Management, http://idea.unalmzl. edu.co, Universidad Nacional de Colombia, Manizales, 2003

Bell, R. and Glade, T: Multi-hazard analysis in natural risk assessments, Risk Analysis, IV, 197-206. 2004.

Birkmann, J. (Ed.): Measuring Vulnerability to Natural Hazards. Towards Disaster Resilient Societies. United Nations, University Press, Tokyo, 2006.

Cardona, O. D. and Hurtado, J. E.: Holistic seismic risk estimation of a metropolitan center, in: Proceedings of 12th World Conference of Earthquake Engineering, Auckland, New Zeland, 2000.

Cardona, O. D.: Holistic evaluation of the seismic risk using complex dynamic systems, Ph.D. thesis, Technical University of Catalonia, Barcelona, Spain, 2001 (in Spanish).

Cardona, O. D., Hurtado, J. E., Duque, G., Moreno, A., Chardon, A. C., Velasquez, L. S., and Prieto, S. D.: Disaster Risk and Risk Management Benchmarking: a methodology based on indicators at National Level, IDB-IDEA Program on Indicators for Disaster Risk Management, Universitad National De Colombian, Manizales, 101 pp., 2004.

Carreño, M., Cardona, O., and Barbat, A.: A disaster risk management performance index, Natural Hazards, 41(1), 1-20, 2007.

CEPAL/BID: A matter of development: how to reduce vulnerability in the face of natural disasters: confronting Natural Disasters: a Matter of Development, Seminar, New Orleans, 25 and 26 March 2000.

CIRC.MIN.LL.PP 352/1987 (Circolare Ministero Dei Lavori Pubblici, N. 352): Prescrizioni inerenti l'applicazione del regolamento sulle dighe di ritenuta approvato con decreto del Presidente della Repubblica 1 Novembre 1959, N. 1363, (G.U. 19-11988, N. 14), 4 Dicembre 1987.

Coburn, A. W., Spence, R. J. S., and Pomonis, A.: Vulnerability and Risk Assessment, 2nd edn., UNDP and Department of Humanitarian Affairs, United Nations, 1994.

Crosta, G. B. and Frattini, P.: Distributed modelling of shallow landslides triggered by intense rainfall, Nat. Hazards Earth Syst. Sci., 3, 81-93, 2003, http://www.nat-hazards-earth-syst-sci.net/3/81/2003/.

Cruden, D. M. and Varnes, D. J.: Landslide types and processes, in: Landslides Investigation and Mitigation, edited by: Turner, A. K. and Schuster, R. L., National Research Council, Transportation Research Board, Washington, DC, 36-75, 1996.

CTR - Carta Tecnica Regionale, available at: http://www.cartografia.regione.lombardia.it/geoportale/ptk? command=openchannel $\backslash \&$ channel=143, last access: April 2007. 
D.LGS 238/2005 - Decreto Legislativo n. 238, “Attuazione della direttiva 2003/105/CE, che modifica la direttiva 96/82/CE, sul controllo dei pericoli di incidenti rilevanti connessi con determinate sostanze pericolose", 21 Settembre 2005.

Dietrich, W. E. and Montgomery, D. R.: Shalstab: a digital terrain model for mapping shallow landslide potential Gradually varied debris flow along a slope, NCASI Technical Report, 29 pp., February 1998.

Dilley, M., Chen, R. S., Deichmann, U., Lerner-Lam, A. L., and Arnold, M.: Natural disaster hotspots: a global risk analysis, The World Bank, Washington, DC, Disaster Risk Management Series No. 5, 132 pp., 2005

Durham, K.: Treating the risks in Cairns, Nat. Hazards, 30, 251261, 2003.

DUSAF - Uso del Suolo Agricolo Forestale, available at: http://www.cartografia.regione.lombardia.it/geoportale/ptk? command=openchannel $\backslash \&$ channel $=157$, last access: April 2007.

ESPON: The Spatial Effects and Management of Natural and Technological Hazards in Europe, Final report of the ESPON Project 1.3.1, 197 pp., 2005.

FEMA: Earthquake Loss Estimation Methodology, HAZUS, Federal Emergency Management Agency, Washington, DC, 1999.

Ferrier, N. and Haque, C. E.: Hazards risk assessment methodology for emergency managers: A standardized framework for application, Nat. Hazards 28(2/3), 271-290, 2003.

Fuchs, S., Heiss, K., and Hübl, J.: Towards an empirical vulnerability function for use in debris flow risk assessment, Nat. Hazards Earth Syst. Sci., 7, 495-506, 2007, http://www.nat-hazards-earth-syst-sci.net/7/495/2007/.

Galli, M. and Guzzetti, F.: Landslide Vulnerability Criteria: A Case Study from Umbria, Central Italy, Environmental Management, 40, 649-664, 2007.

Glade, T.: Vulnerability assessment in landslide risk analysis, Die Erde, 134, 121-138, 2003.

Granger, K. and Hayne, M. (Eds): Natural hazards and the risks they pose to South-East Queensland, Australian Geological Survey Organisation, Canberra, 2001.

Granger, K., Jones, T., Leiba, M., and Scott, G.: Community Risk in Cairns: A Multi-Hazard Risk Assessment, Australian Geological Survey Organisation, Canberra, 1999.

Gruppo di lavoro CPTI: Catalogo Parametrico dei Terremoti Italiani, versione 2004 (CPTI04), INGV, Bologna, 2004.

Hungr, O. and Evans, S. G.: Engineering evaluation of fragmental rockfall hazards, in: Proc. 5th International Symposium on Landslides, University of Lausanne, Lausanne, 1, 685-690, 1988.

INAIL - Istituto Nazionale per l'assicurazione contro gli infortuni sul lavoro, available at: www.inail.it, last access: April 2007.

ISTAT - Istituto nazionale di statistica, available at: http://www. istat.it/, last access: April 2007.

Jaboyedoff, M. and Labiouse, V.: Preliminary assessment of rockfall hazard based on GIS data, in: ISRM 2003 - Technology roadmap for rock mechanics, South African Institute of Mining and Metallurgy, 1, 575-578, 2003.

Kaplan, S. and Garrick, B. J.: On the quantitative definition of risk, Risk analysis, 1(1), 11-27, 1981.

Klecka, W. R.: Discriminant Analysis, Sage Publications, 1980

Lari, S.: Heuristic and quantitative assessment of geological, technological and integrated risk. Evaluation at different scales of un- certainty propagation and of mitigation interventions, $\mathrm{Ph} . \mathrm{D}$. thesis, Università degli Studi di Milano Bicocca, 2009.

Masure, P.: Variables and indicators of vulnerability and disaster risk for land-use and urban on territorial planning, IDB/IDEA Programa de induicadores para la gestion de riesgos, Universidad Nacional de Colombia, Manizales, 2003.

Middelmann, M. and Granger, K. (Eds): Community risk in Mackay: A multi-hazard risk assessment, Australian Geological Survey Organisation, Canberra, 2000.

MISURC - Mosaico Informatizzato degli Strumenti Urbanistici Comunali, available at: http://www.cartografia.regione.lombardia. it/geoportale/ptk?command=openchannel $\backslash \&$ channel=154, last access: April 2007.

MPS Working Group: Redazione della mappa di pericolosità sismica prevista dall'Ordinanza PCM 3274 del 20 Marzo 2003, Rapporto Conclusivo per il Dipartimento della Protezione Civile, INGV, Milano-Roma, 65 pp.+5 appendixes, available at: http://zonesismiche.mi.ingv.it (last access: April 2007), April 2004.

NACE rev2: Regolamento (CE) n. 1893/2006 Del Parlamento Europeo E Del Consiglio, 20 Dicembre 2006.

NORSOK Standard: Z-013 Risk and emergency preparedness analysis NTC (Norwegian Technology Centre), Oslo, Norway, 2001.

PAI - Piano stralcio di Assetto Idrogeologico, available at: http://www.adbpo.it, last access: April 2007.

Porter, K. A., Kiremidjian, A. S., and LeGrue, J. S.: Assemblybased vulnerability of buildings and its use in performance evaluation, Earthquake spectra, 17(2), 291-312, 2001.

PROGETTO IFFI - Inventario dei Fenomeni Franosi in Lombardia, available at: http://www.cartografia.regione.lombardia.it/ geoportale/ptk?command=openchannel $\backslash \&$ channel=152, last access: April 2007.

PS267 - Piano straordinario per le aree a rischio idrogeologico molto elevato, available at: http://www.adbpo.it, last access: April 2007.

Regione Lombardia (D.G. Territorio ed urbanistica): Il bacino Lariano - nuove tecnologie per la generazione di un modello tridimensionale del terreno, CD, edizione 2007.

Regione Lombardia: Piano Antincendi Boschivi (AIB), available at: http://www.incendiboschivi.regione.lombardia.it/ (last access: April 2007), 2006.

Regione Lombardia: PRIM 2007-2010, Programma Regionale Integrato di Mitigazione dei Rischi, Studi Preparatori - Incidenti ad elevata rilevanza sociale in Lombardia, Regione Lombardia Protezione civile, Prevenzione e Polizia Locale, 2007.

Regione Lombardia: PRIM 2007-2010, Programma Regionale Integrato di Mitigazione dei Rischi, Studi Preparatori - Rischi maggiori in Lombardia, Regione Lombardia - Protezione civile, Prevenzione e Polizia Locale, 2007.

Regione Lombardia: PRIM 2007-2010, Programma Regionale Integrato di Mitigazione dei Rischi, Studi Preparatori - Il rischio integrato in Lombardia: misurazioni di livello regionale e individuazione delle zone a maggiore criticità, Regione Lombardia Protezione civile, Prevenzione e Polizia Locale, 2007.

Roberds, W.: Estimating temporal and spatial variability and vulnerability, in: Landslide Risk Mangement, edited by: Hungr, O., Fell, R., Couture, R., and Eberhardt, E., Technology \& Engineering, 776 pp., 2005.

Saaty, T. L.: Multicriteria Decision Making: The Analytic Hierar- 
chy Process, AHP Series, RWS Publications, 1, 502 pp., 1990.

SIAB - Sistema Informativo Antincendio Boschivo - D.G. Protezione Civile Prevenzione Polizia Locale Regione Lombardia, data base Regione Lombardia, 2002.

SIRF-CESI, mappe di densità di fulminazione 1996-2005, available at: http://www.fulmini.it/, last access: April 2007

SIRVAL - Sistema Informativo Regionale Valanghe, available at: http://www.cartografia.regione.lombardia.it/geoportale/ptk? command=openchannel $\backslash \&$ channel=152, last access: April 2007

Stamatelatos, M. and Apostolakis, G.: Probabilistic Risk Assessment Procedures Guide for NASA Managers and Practitioners v1.1, NASA, Safety and Mission Assurance, 2002.

Tyagunov, S., Heneka, P., Zschau J., Ruck, B., and Kottmeier, C.: CEDIM: From Multi-Hazards to Multi-Risks, paper presented at Amonia Conference, available at:

http://www.cedim.de/english/904.php, December 2005.
UNDP (United Nations Development Programme Bureau for Crisis Prevention and Reco): Reducing disaster risk: a challenge for development, New York, NY, United Nation Development Programme, printed by: John S. Swift Co., USA, 2004.

USACE: Economic Guidance Memo (EGM) 01-03, Generic DepthDamage Relationships Washington, DC, 2000.

Van Westen, C. J., Montoya, L., and Boerboom, L.: Multi-Hazard Risk Assessment using GIS in urban areas: A case study for the city of Turrialba, Costa-Rica, in: Proc. Regional workshop on Best Practise in Disaster Mitigation, Bali, 120-136, 2002.

Zadeh, L. A.: Fuzzy sets, Information and control, 8, 338-353, 1965. 